OPEN ACCESS

Edited by:

Wolfgang Schoppek,

University of Bayreuth, Germany

Reviewed by:

Natassia Goode,

University of the Sunshine Coast,

Australia

Marc Halbrügge,

Technische Universität Berlin,

Germany

*Correspondence:

Heinz-Martin Süß

heinz-martin.suess@ovgu.de

Specialty section:

This article was submitted to

Cognitive Science,

a section of the journal

Frontiers in Psychology

Received: 06 October 2017 Accepted: 13 April 2018

Published: 08 May 2018

Citation:

SüB H-M and Kretzschmar A (2018) Impact of Cognitive Abilities and Prior Knowledge on Complex Problem Solving Performance - Empirical Results and a Plea for Ecologically Valid Microworlds.

Front. Psychol. 9:626. doi: 10.3389/fpsyg.2018.00626

\section{Impact of Cognitive Abilities and Prior Knowledge on Complex Problem Solving Performance - Empirical Results and a Plea for Ecologically Valid Microworlds}

\author{
Heinz-Martin Süß ${ }^{1 *}$ and André Kretzschmar ${ }^{2}$ \\ ${ }^{1}$ Institute of Psychology, Otto-von-Guericke University Magdeburg, Magdeburg, Germany, ${ }^{2}$ Hector Research Institute of \\ Education Sciences and Psychology, University of Tübingen, Tübingen, Germany
}

The original aim of complex problem solving (CPS) research was to bring the cognitive demands of complex real-life problems into the lab in order to investigate problem solving behavior and performance under controlled conditions. Up until now, the validity of psychometric intelligence constructs has been scrutinized with regard to its importance for CPS performance. At the same time, different CPS measurement approaches competing for the title of the best way to assess CPS have been developed. In the first part of the paper, we investigate the predictability of CPS performance on the basis of the Berlin Intelligence Structure Model and Cattell's investment theory as well as an elaborated knowledge taxonomy. In the first study, 137 students managed a simulated shirt factory (Tailorshop; i.e., a complex real life-oriented system) twice, while in the second study, 152 students completed a forestry scenario (FSYS; i.e., a complex artificial world system). The results indicate that reasoning - specifically numerical reasoning (Studies 1 and 2) and figural reasoning (Study 2) - are the only relevant predictors among the intelligence constructs. We discuss the results with reference to the Brunswik symmetry principle. Path models suggest that reasoning and prior knowledge influence problem solving performance in the Tailorshop scenario mainly indirectly. In addition, different types of system-specific knowledge independently contribute to predicting CPS performance. The results of Study 2 indicate that working memory capacity, assessed as an additional predictor, has no incremental validity beyond reasoning. We conclude that (1) cognitive abilities and prior knowledge are substantial predictors of CPS performance, and (2) in contrast to former and recent interpretations, there is insufficient evidence to consider CPS a unique ability construct. In the second part of the paper, we discuss our results in light of recent CPS research, which predominantly utilizes the minimally complex systems (MCS) measurement approach. We suggest ecologically valid microworlds as an indispensable tool for future CPS research and applications.

Keywords: complex problem solving, microworlds, minimally complex systems, intelligence, investment theory, knowledge assessment, working memory, Brunswik symmetry 


\section{INTRODUCTION}

People are frequently confronted with problems in their daily lives that can be characterized as complex in many aspects. A subset of these problems can be described as interactions between a person and a dynamic system of interconnected variables. By manipulating some of these variables, the person can try to move the system from its present state to a goal state or keep certain critical variables within tolerable ranges. Problems of this kind can be simulated using computer models (aka microworlds), offering an opportunity to observe human behavior in realistic problem environments under controlled conditions.

The study of human interaction with complex computersimulated problem scenarios has become an increasingly popular field of research in numerous areas of psychology over the past four decades. For example, computer models have been built to simulate the job of a small-town mayor (Dörner et al., 1983), a production plant operator (Bainbridge, 1974; Morris and Rouse, 1985), a business manager (Putz-Osterloh, 1981; Wolfe and Roberts, 1986), a coal-fired power plant operator (Wallach, 1997), and a water distribution system operator (Gonzalez et al., 2003). Real-time simulations have put users in the role of the head of a firefighting crew (Brehmer, 1986; Rigas et al., 2002) or an air traffic controller (Ackerman and Kanfer, 1993). In experimental psychology, research on complex problem solving (CPS) has sought to formally describe simulations (e.g., Buchner and Funke, 1993; Funke, 1993), the effects of system features on task difficulty (e.g., Funke, 1985; Gonzalez and Dutt, 2011), the role of emotions (e.g., Spering et al., 2005; Barth and Funke, 2010), and the effects of practice and training programs (e.g., Kluge, 2008b; Kretzschmar and Süß, 2015; Goode and Beckmann, 2016; Engelhart et al., 2017; see also Funke, 1995, 1998). Differential and cognitive psychology research has investigated the psychometrical features of CPS assessments (e.g., Rigas et al., 2002), the utility of computational models for explaining CPS performance (e.g., Dutt and Gonzalez, 2015), the relationship between CPS performance and cognitive abilities (e.g., Wittmann and Süß, 1999), and its ability to predict real-life success criteria (e.g., Kersting, 2001). For detailed summaries of different areas of CPS research, see Frensch and Funke (1995) and Funke (2006).

Meanwhile, many researchers have moved away from complex real life-oriented systems (CRS) to complex artificial world systems (CAS) in order to increase the psychometric quality of measures and to control for the effects of preexisting knowledge (e.g., Funke, 1992; Wagener, 2001; Kröner et al., 2005). This development ultimately culminated in the minimally complex systems (MCS) approach (Greiff et al., 2012), also known as the multiple complex systems approach (e.g., Greiff et al., 2015a). This approach has recently become prominent in educational psychology (e.g., Greiff et al., 2013b; Sonnleitner et al., 2013; Kretzschmar et al., 2014; OECD, 2014; Csapó and Molnár, 2017). In addition, this shift has led to the question of what are and are not complex problems, with some researchers questioning the relevance of MCS as a tool for CPS research and the validity of the conclusions drawn from them (e.g., Funke, 2014; Dörner and Funke, 2017; Funke et al., 2017; Kretzschmar, 2017).
Originally, simulated dynamic task environments were used to reproduce the cognitive demands associated with real-life problems in the laboratory (Dörner et al., 1983; Dörner, 1986). These environments have several features: (1) Complexity: Many aspects of a situation must be taken into account at the same time. (2) Interconnectivity: The different aspects of a situation are not independent of one another and therefore cannot be controlled separately. (3) Intransparency: Only some of the relevant information is made available to the problem solver. (4) Dynamics: Changes in the system occur without intervention from the agent. (5) Polytely: The problem solver must sometimes pursue multiple and even contradictory goals simultaneously. (6) Vagueness: Goals are only vaguely formulated and must be defined more precisely by the problem solver. Whereas older microworlds featured all of these characteristics to a considerable extent, more recent approaches such as MCS have substituted complexity and ecological validity (i.e., the simulation's validity as a realistic problem-solving environment allowing psychological statements to be made about the real world; see Fahrenberg, 2017) for highly reliable assessment instruments by simulating tiny artificial world relationships (e.g., Greiff et al., 2012; Sonnleitner et al., 2012).

The present paper is divided into two parts. In the first part, we deal with one of the oldest but still an ongoing issue in the area of CPS research: the cognitive prerequisites of CPS performance. In two different studies, we used microworlds (CRS and CAS) to empirically investigate the impact of cognitive abilities (i.e., intelligence and working memory capacity) and prior knowledge on CPS performance. In doing so, we considered the impact of the Brunswik symmetry principle, which effects the empirical correlations between hierarchical constructs (e.g., Wittmann, 1988). Integrating our results with previous CPS research, we review the basis and empirical evidence for 'complex problem solving ability' as a distinct cognitive construct. In the second part of the paper, we discuss our approach and results in light of recent problem solving research, which predominantly utilizes the MCS approach. Finally, we conclude with some recommendations for future research on CPS and suggest ecologically valid microworlds as tools for research and applications.

\section{PART I: EMPIRICAL INVESTIGATION OF THE COGNITIVE PREREQUISITES OF COMPLEX PROBLEM SOLVING PERFORMANCE}

\section{Intelligence and Complex Problem Solving}

At the beginning of complex problem solving (CPS) research, CPS pioneers raised sharp criticisms of the validity of psychometric intelligence tests (Putz-Osterloh, 1981; Dörner et al., 1983; Dörner and Kreuzig, 1983). These measures, derisively referred to as "test intelligence," are argued to be bad predictors of performance on partially intransparent, illdefined complex problems. In contrast to simulated scenarios, intelligence test tasks are less complex, static, transparent, 
and well-defined problems that do not resemble most reallife demands in any relevant way. Zero correlations between intelligence measures and CPS performance were interpreted as evidence of the discriminant validity of CPS assessments, leading to the development of a new ability construct labeled complex problem solving ability or operative intelligence (Dörner, 1986). However, no evidence of the convergent validity of CPS assessments or empirical evidence for their predictive validity with regard to relevant external criteria or even incremental validity beyond psychometric intelligence tests have been presented.

By now, numerous studies have investigated the relationship between control performance on computer-simulated complex systems and intelligence. Whereas Kluwe et al. (1991) found no evidence of a relationship in an older review, more recent studies have found correlations that are substantial but still modest enough to argue in favor of a distinct CPS construct (e.g., Wüstenberg et al., 2012; Greiff et al., 2013b; Sonnleitner et al., 2013). In a more recent meta-analysis, Stadler et al. (2015) calculated the overall average effect size between general intelligence ( $\mathrm{g}$ ) and CPS performance to be $r=0.43$ (excluding outliers, $r=0.40$ ), with a $95 \%$ confidence interval ranging from 0.37 to 0.49 . The mean correlation between CPS performance and reasoning was $r=0.47$ (95\% CI: 0.40 to 0.54$)$. The relationship with $\mathrm{g}$ was stronger for MCS $(r=0.58)$ than CRSs $(r=0.34)^{1}$. From our point of view, this difference results from the higher reliability of MCS but also a difference in cognitive demands. MCS are tiny artificial world simulations in which domain-specific prior knowledge is irrelevant. Complex real lifeoriented tasks, however, activate preexisting knowledge about the simulated domain. This knowledge facilitates problem solving; in some cases, the problems are so complex that they cannot be solved at all without prior knowledge (e.g., Hesse, 1982).

The main issues with many complex real life-oriented studies that investigated the relation between intelligence and CPS performance concern the ecological validity of the simulations and the psychometric quality of the problem-solving performance criteria. This often leads to much larger confidence intervals in their correlations with intelligence compared to minimal complex tasks (Stadler et al., 2015). When the goals of a simulation are multiple and vaguely defined, the validity of any objective criterion is questionable since it might not correspond to the problem solver's subjective goal. However, people are unlikely to face a single, well-defined goal in real-life problems, limiting the ecological validity of such systems - despite the fact that a well-defined goal is a necessary precondition for assessing problem solving success in a standardized way, which is necessary in order to compare subjects' performance. Moreover, single problem solving trials produce only "single act criteria" (Fishbein and Ajzen, 1974), criticized as "one-itemtesting" (e.g., Wüstenberg et al., 2012), the reliability of which is severely limited. Performance scores must be aggregated via repeated measurements to increase the proportion of reliable

\footnotetext{
${ }^{1}$ The correlation between complex real life-oriented systems and reasoning was not reported, nor was the effect of outliers on relationships other than that between CPS and g.
}

variance that can be predicted (e.g., Wittmann and Süß, 1999; Rigas et al., 2002). The MCS has implemented these steps, resulting in strong reliability estimates (e.g., Greiff et al., 2012; Sonnleitner et al., 2012).

Another crucial issue with regard to the relation between intelligence and CPS performance is the operationalization of intelligence. Numerous prior studies have used a measure of general intelligence $(g)$ to predict problem solving success. Since $g$ is a compound of several more specific abilities, $g$ scores comprise variance in abilities relevant to complex problem solving as well as variance in irrelevant abilities. According to Wittmann's (1988) multivariate reliability theory and the Brunswik symmetry principle (see also Wittmann and Süß, 1999), this results in an asymmetric relationship between predictor and criterion, attenuating their correlation. More specific subconstructs of intelligence might be more symmetrical predictors because they exclude irrelevant variance. In our view, controlling complex systems requires a great deal of reasoning ability (e.g., Süß, 1996; Wittmann and Süß, 1999; Kröner et al., 2005; Sonnleitner et al., 2013; Kretzschmar et al., 2016, 2017). Inductive reasoning is required to detect systematic patterns within the ever-changing system states and develop viable hypotheses about the system's causal structure. Deductive reasoning is necessary to infer expectations about future developments from knowledge of causal connections and deduce more specific goals from higherorder goals. Abilities such as perceptual speed (except in real-time simulations), memory, and verbal fluency, meanwhile, should be less relevant for success in complex problem solving. In this sense, it is an open question in CPS research whether WMC, as a more basic ability construct (e.g., Süß et al., 2002; Oberauer et al., 2008), is a more symmetrical predictor of CPS performance than reasoning (for an overview of previous findings, see Zech et al., 2017).

In summary, a substantial correlation between intelligence and CPS performance measured with real life-oriented microworlds can be expected if (1) sufficient reliability of the CPS measures is ensured (e.g., aggregation via repeated measures), and (2) the best symmetrical intelligence construct is used (e.g., reasoning instead of general intelligence or perceptual speed).

\section{Knowledge and Complex Problem Solving}

In addition to the debate about intelligence's contribution to complex problem solving, many researchers have pointed out the significance of knowledge for the successful control of complex systems (e.g., Bainbridge, 1974; Dörner et al., 1983; Chi et al., 1988; Goode and Beckmann, 2010; Beckmann and Goode, 2014). Expert knowledge is sometimes claimed to be the only important predictor of real-life problem solving success (Ceci and Liker, 1986), while others point out that both intelligence and knowledge contribute substantially to predicting job performance (Schmidt, 1992), which certainly includes complex problem solving.

Scenarios that accurately simulate real-world relationships provide an opportunity to draw on preexisting knowledge about the part of reality being simulated. That being said, a 
simulation never is exactly equivalent to what the problem solver has experienced before. Experts in a domain can make use of their knowledge to operate a simulation within that domain, but they are not automatically experts in the simulated scenario. The application of domain knowledge to the simulation requires a considerable amount of transfer. Following Cattell's investment theory (Cattell, 1987), we assume that intelligence, and particularly reasoning, plays an important role in mediating this transfer. Therefore both, intellectual abilities, particularly reasoning and prior knowledge of the simulated domain, should be powerful predictors of complex problem solving success, although the effect of intelligence has been found to be mainly indirect, mediated through knowledge (Schmidt et al., 1986; Schmidt, 1992).

The knowledge relevant for successfully controlling a complex system can be differentiated conceptually on two dimensions. First, knowledge about the system can be distinguished from knowledge about appropriate actions. System knowledge is knowledge about the features and structure of a system, such as what variables it consists of, how these variables are related, and what kind of behaviors the system tends to exhibit. Action-related knowledge is knowledge about what to do in order to pursue a given goal. In contrast to system knowledge, action knowledge is always bound to a specific goal. Studies by Vollmeyer et al. (1996) provided evidence for the distinction between system knowledge and action knowledge: Participants who acquired knowledge about a system during an exploration phase with or without a given goal performed equally well on a subsequent test trial with the same goal. However, the group which had not been given a specific goal during the exploration phase outperformed the group with the specific goal on a test with a new goal. Presumably, the specific goal group had learned mainly action knowledge, whereas the other group had acquired more system knowledge, which was then transferable to new goals.

A second distinction, independent of the first, exists between declarative and procedural knowledge. Declarative knowledge is knowledge that a person can represent symbolically in some way - verbally, graphically or otherwise. Declarative knowledge can be expressed as accurate answers to questions. Procedural knowledge, on the other hand, can be expressed only through accurate performance. The distinction between declarative and procedural knowledge is based on the conceptual difference between "knowing that" and "knowing how" (Ryle, 1949).

While system knowledge and action knowledge differ in content, declarative and procedural knowledge are different forms of knowledge. Therefore, the two dimensions can be conceived of as orthogonal. System knowledge and action knowledge can both be declarative: A person can talk about which variables are causally related to which other variables, but also about what to do in order to keep the system stable. Similarly, both system knowledge and action knowledge can also be procedural: Knowing how to stabilize a system without being able to express it is procedural action knowledge. Being able to mentally simulate a system or diagnose what variable is causing a disturbance without being able to give a full verbal account of the reasons is indicative of procedural system knowledge. Several studies have found that people do not improve their problemsolving performance in controlling or repairing complex systems after receiving instructions in the form of declarative system knowledge (e.g., Morris and Rouse, 1985; Kluge, 2008b; but see Goode and Beckmann, 2010), and declarative knowledge sometimes is not correlated with problem solving performance (e.g., Berry and Dienes, 1993). Therefore, we must consider the possibility that procedural knowledge is part of the relevant knowledge base that guides a person's actions within complex dynamic environments.

In summary, prior domain knowledge must be considered as an additional substantial predictor of CPS performance. However, differentiating between different types of knowledge is necessary in order to explain CPS performance. In addition, different semantic embeddings (i.e., CRS vs. CAS) have different demands with regard to preexisting knowledge.

\section{The Present Study}

The first goal of the two studies presented in this paper was to test the hypothesized criterion validity of reasoning in predicting problem solving performance in complex dynamic tasks. In addition, considering the Brunswik symmetry principle (Wittmann, 1988), we explored the predictive validity of additional more specific or more general intelligence constructs. Our investigation was based on the Berlin Intelligence Structure Model (BIS), a hierarchical and faceted model of intelligence (Jäger, 1982, 1984; for a detailed description in English, see Süß and Beauducel, 2015). The BIS differentiates intellectual abilities along two facets. The operation facet comprises four abilities: Reasoning $(\mathrm{R})$ includes inductive, deductive and spatial reasoning and is equivalent to fluid intelligence (Gf). Creativity (C) refers to the ability to fluently produce many different ideas. Memory $(\mathrm{M})$ refers to the ability to recall lists and configurations of items a few minutes after having learned them (episodic memory), whereas speed (S) refers to the ability to perform simple tasks quickly and accurately (perceptual speed). The second facet is postulated to include three contentrelated abilities: verbal (V), numerical (N) and figural-spatial (F) intelligence. Cross-classifying the four operational and three content abilities results in 12 lower-order cells. In addition, general intelligence is conceptualized as an overarching factor (Figure 1). For summaries of the validity and scope of the BIS, see the handbook for the BIS Test (Jäger et al., 1997) as well as Süß and Beauducel $(2005,2015)$.

In the second study, we included WMC as an additional predictor. Working memory is considered the most important cognitive resource for complex information processing, which includes reasoning (e.g., Kyllonen and Christal, 1990; Süß et al., 2002; Conway et al., 2003), language comprehension (e.g., King and Just, 1991), and math performance (e.g., Swanson and Kim, 2007). Consequently, previous research has found a significant relation between WMC and CPS (e.g., Wittmann and Süß, 1999; Bühner et al., 2008; Schweizer et al., 2013; Greiff et al., 2016). However, whether the more basic construct (i.e., WMC) is a stronger symmetrical predictor of CPS than reasoning from the perspective of the Brunswik symmetry principle (Wittmann, 1988) is not clear (for an overview, see Zech et al., 2017). 




FIGURE 1 | The Berlin Intelligence Structure Model (BIS), and the number of tasks for each cell applied in Study 1 (in brackets, Study 2). In the BIS, four operation ability constructs are crossed with three content constructs, yielding twelve cells. On a higher level of aggregation, general intelligence integrates the primary factors for each facet.

For example, Wittmann and Süß, 1999 demonstrated that WMC has incremental validity in predicting CPS performance beyond intelligence. Bühner et al. (2008) could not confirm this result, but their study relied upon narrow operationalizations.

The second goal of the two studies presented in this paper was to investigate the relation between knowledge and complex problem solving performance. We attempted to measure knowledge about complex systems in several categories. We focused on declarative knowledge in the form of both system knowledge and action knowledge because assessing declarative knowledge is straightforward. We also attempted to measure procedural knowledge, despite the fact that no evidence has ever been put forward that responses to complex problem-solving tests exclusively reflect procedural knowledge and not declarative knowledge. Based on Cattell's investment theory (Cattell, 1987), we assumed that knowledge represents invested intelligence and examined whether the predictive effect of intelligence on CPS performance is completely mediated by prior knowledge.

We applied a CRS (i.e., a microworld with a realistic semantic embedding) in the first study, whereas we used a CAS (i.e., a microworld with an artificial semantic embedding) in the second study. Hence, the importance of preexisting knowledge with regard to CPS performance should differ between the two studies.

\section{STUDY 1}

In the first study, we used a complex real life-oriented simulation to examine the criterion validity of intelligence, particularly reasoning, and prior knowledge for control performance in a simulated shirt factory (Tailorshop). As we used a very comprehensive assessment of intelligence and knowledge, we were also interested in exploring the predictive validity of additional, more specific constructs in order to investigate the influence of the Brunswik symmetry principle (Wittmann, 1988) on the relation between intelligence, knowledge and CPS performance.

\section{Method}

\section{Participants}

One hundred and thirty-seven students from 13 high schools in Berlin took part in the experimental study in 1990 (Süß et al., 1991). They had all participated in a similar study 1 year before in which they had taken prior versions of the BIS Test and the knowledge tests and had explored the Tailorshop system (Süß et al., 1993a,b). Their mean age was 17.6 years $(S D=0.67)$, and $40.9 \%$ were female. The participants were fully informed about the study and the voluntary nature of their participation, and anonymity was guaranteed. Written informed consent was obtained from school principals and the state school board. Subjects who withdrew from the study were required to attend other school lessons. Both Berlin studies were published in German only; a full report including the longitudinal results can be found in Süß (1996). In this paper, we report the results of the second Berlin study (here labeled Study 1) to make the results available for international readers and to discuss the two studies in the light of recent developments in CPS research.

\section{Materials}

\section{Problem solving}

An extended version of the Tailorshop system (Funke, 1983; Danner et al., 2011), originally designed by D. Dörner and first used in a published study by Putz-Osterloh (1981), was 
applied as a CRS (Süß and Faulhaber, 1990). Additional minor modifications were made in the system to resolve issues with the validity of the problem-solving score that had become apparent in the study conducted 1 year before (Süß et al., 1993a,b). Tailorshop is a computer simulation of a shirt factory. The system has 27 variables: 10 are exogenous variables that can be manipulated directly, and 17 are endogenous variables computed by the simulation. Figure 2 provides a screenshot of the system, and Figure 3 an overview of the variables and their interconnections.

The system was run on a personal computer. All variables were presented in a single menu, and the values of exogenous variables could be selected via a pull-down menu. After planning all decisions, the operator ran the simulation for one virtual month. A complete trial consisted of twelve simulation cycles corresponding to 1 year of management. To obtain two independent indicators of problem solving success, participants worked on two versions of Tailorshop with different starting values corresponding to different shirt factories and different economic conditions. Problem solving performance was measured by participants' total assets after 12 simulated months. Since the distribution of raw scores deviated considerably from a normal distribution, we transformed them into rank scores and aggregated participants' ranks from the two simulation runs into one total score.

\section{Intelligence test}

To assess intellectual abilities, we used a prior version of the BIS Test (Jäger et al., 1997; for a full English description see Süß and Beauducel, 2015; for prior test versions see Süß, 1996). This test consists of three to five different tasks for each of the 12 cells in the matrix structure of the BIS. Each task assigned to a cell in the model is used to measure one operation ability as well as one content ability. The four operation abilities are thus measured with scales consisting of 9-15 tasks each and balanced over the three content categories. Analogously, content abilities are measured with scales consisting of 15 tasks across the four different operation abilities. Thus, the same variables are used in different ways for different scales. The scales for one facet are built by aggregating variables that are distributed in a balanced way over the other facet. This suppresses unwanted variance, i.e., the variance associated with factors from the other facet (Wittmann, 1988). However, the scores for operation abilities and content abilities are not statistically independent. An indicator of general intelligence is built by aggregating either the operation scores or content scores.

\section{Knowledge tests}

Preexisting general economics knowledge was assessed with an age-normed economics test (Deutsche Gesellschaft für Personalwesen [DGP], 1986, with a few questions added from the economics test from Krumm and Seidel, 1970) $)^{2}$. The questionnaire consisted of 25 multiple-choice items on the meaning of technical terms from the domain of economics.

\footnotetext{
${ }^{2}$ Participants only took the economics test in the first Berlin study, i.e., these data were assessed 1 year before all others reported here.
}

A new test was developed to assess system-specific knowledge about Tailorshop (Kersting and Süß, 1995). This test had two parts, one for system knowledge and one for action knowledge.

System knowledge refers to knowledge about features of individual variables (e.g., development over time, degree of connectedness with other variables) and about relationships between variables in a system. The system knowledge part of the test was developed in accordance with test construction principles for optimizing content validity (Klauer, 1984; Haynes et al., 1995). It consisted of three scales:

(1) Multiple choice questions about the connections between two variables. One out of six statements in the following form had to be selected as correct:

(a) An increase in variable $\mathrm{X}$ increases variable $\mathrm{Y}$.

(b) An increase in variable $X$ decreases variable $Y$.

(c) An increase in variable $Y$ increases variable $X$.

(d) An increase in variable $Y$ decreases variable $X$.

(e) Variable $\mathrm{X}$ and variable $\mathrm{Y}$ interact, that is, they both depend on one another.

(f) (a) through (e) are false.

There were 20 questions of this type.

(2) Questions about hypotheses concerning single variables: Participants had to evaluate statements about the regular behavior of individual system variables, e.g., "The price of shirts rises and falls by chance" (which is false) or "Production depends - among other factors - on my workers' motivation, which in turn depends on the level of wages" (which is true). The scale consisted of 25 independent items.

(3) Arrow test for connections among multiple variables: Sets of four variables were represented by labeled boxes in a diamond-shaped arrangement. Participants had to draw arrows connecting the variables that had a direct causal connection in the system, and designate the direction of correlation with a plus or minus sign (as in Figure 3). Each of the six possible pairings in a set was counted as an independent item that was marked as either correct or incorrect, yielding a total of 42 items.

Action knowledge refers to knowledge about appropriate actions in a certain situation, given a certain goal. It was assessed in this study via two subtests. The test of declarative action knowledge presented "rules of thumb" for successfully managing the Tailorshop simulation, which had to be evaluated as correct or incorrect. Half of the 12 rules were correct, i.e., they were helpful in obtaining high total assets within 12 months, while the other half were incorrect.

In the second subtest, participants were given a system state in the form of a screen display. They were given the goal of maximizing or minimizing a certain system variable, for example, minimizing the number of shirts in the store. They had to select which one out of six alternative decision patterns would be best-suited to reaching this goal in the next simulation cycle. This subtest consisted of six items with different system states, goals, and decision options. In contrast to the 


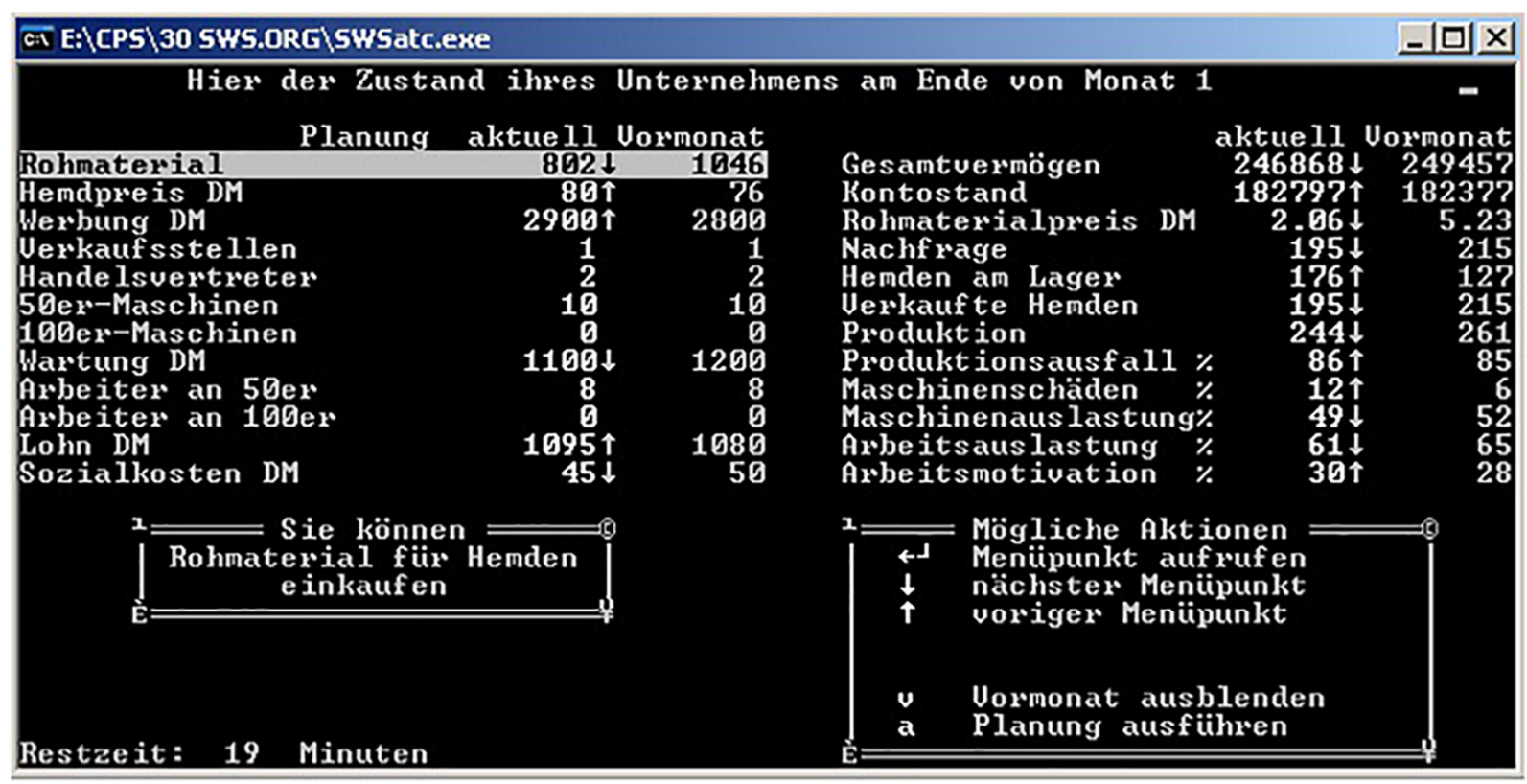

FIGURE 2 | Screenshot of the exploration phase of the Tailorshop system as applied in Study 1.

declarative questions, this task did not require participants to explicit declare rules for action. Instead, the rules governing their decision-making remained implicit, providing a good opportunity to capture task relevant procedural knowledge. Thus, we will refer to this subscale as procedural action knowledge.

Sum scores were built for each subtest and a total score was calculated by aggregating the subtest scores, weighted equally.

Each type of question was introduced by the experimenter with one or two examples. There was no time limit, but participants were instructed not to spend too much time on any single question.

\section{Procedure}

The students took tests on 2 days for 5-6 h each. On the first day, they worked on the BIS Test and the general economics test as well as some further questionnaires. Testing was done in groups of 20-30 in school classrooms. On the second day, participants were first introduced to the Tailorshop system via detailed instructions, including two standardized practice cycles guided by the experimenter. Afterward, the students in the sample were randomly divided into three groups, and two groups were given additional opportunities to acquire system-specific knowledge. ${ }^{3}$ Next, system-specific knowledge was assessed (time T1) by instructing participants to build hypotheses about Tailorshop on basis of their (superficial)

\footnotetext{
${ }^{3}$ The first group could explore the system for $30 \mathrm{~min}$ on their own (exploration group), while the second group could study the system's causal model for $30 \mathrm{~min}$ following standardized instructions (instructions group). The third group had no opportunity to acquire additional system-specific knowledge (control group). In this paper, we use the results for the full sample without considering the experimental variations. Experimental results and group-specific results are reported in Süß (1996).
}

experience with the system. Participants then tried to manage the Tailorshop twice for 12 simulated months. Finally, systemspecific knowledge was tested again (time T2). The knowledge test took about $80 \mathrm{~min}$ the first time and about $60 \mathrm{~min}$ the second time. Each problem solving trial lasted about $50 \mathrm{~min}$. The participants took these tests in smaller groups at the university's computer lab.

\section{Results}

We will first present the results of separate analyses of the relationship between problem solving performance and different groups of predictors. Then, we integrate all the variables into a path model. Ten participants had missing data for the economics knowledge test. Thus, we applied the full information maximum likelihood (FIML) procedure to account for the missing data. See Table 1 for descriptive statistics and the full correlation matrix.

\section{Complex Problem Solving and Intelligence}

The parallel-test reliability of problem solving performance was $r=0.67(p<0.01)$. This indicates that the criterion measures had satisfactory reliability and justifies their aggregation into a single score. Two multivariate regressions were computed with the aggregated performance criterion, first with the four operation scales and then with the three content scales of the BIS as predictors. The results are summarized in Table 2 (upper half, correlations in brackets).

Among the operation scales, reasoning $(r=0.34, p<0.01)$ was as expected significantly correlated with problem-solving success, furthermore, creativity $(r=0.22, p=0.01)$ as well. In the regression model, however, only reasoning had a significant beta weight $(\beta=0.43, p<0.01)$. Among the content scales, only 


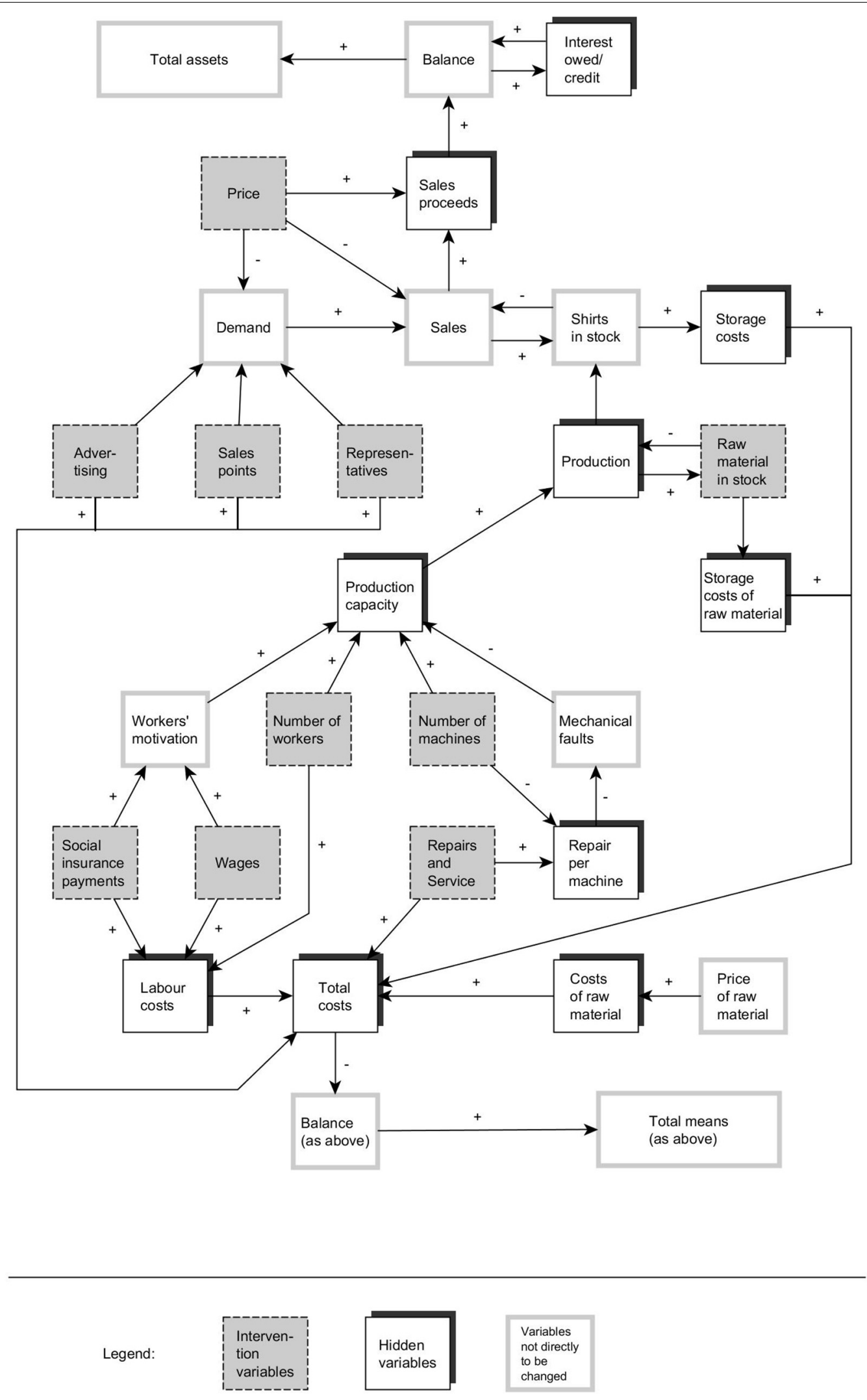

FIGURE $\mathbf{3}$ | The causal structure of the Tailorshop system. 
TABLE 1 | Study 1: Means, standard deviations, and correlations.

\begin{tabular}{|c|c|c|c|c|c|c|c|c|c|c|c|c|}
\hline Variable & $M$ & $S D$ & 1 & 2 & 3 & 4 & 5 & 6 & 7 & 8 & 9 & 10 \\
\hline (1) BIS: g & -0.03 & 6.76 & & & & & & & & & & \\
\hline (2) BIS: Speed & -0.02 & 2.30 & $0.77^{* *}$ & & & & & & & & & \\
\hline (3) BIS: Memory & -0.02 & 2.36 & $0.66^{* *}$ & $0.31 * *$ & & & & & & & & \\
\hline (4) BIS: Creativity & 0.00 & 2.22 & $0.66^{* *}$ & $0.38^{* *}$ & $0.21^{*}$ & & & & & & & \\
\hline (5) BIS: Reasoning & 0.00 & 2.51 & $0.79 * *$ & $0.53^{* *}$ & $0.35^{* *}$ & $0.35^{* *}$ & & & & & & \\
\hline (6) BIS: Verbal & 0.00 & 2.60 & $0.78^{* *}$ & $0.57^{* *}$ & $0.52^{* *}$ & $0.57^{* *}$ & $0.59^{* *}$ & & & & & \\
\hline (7) BIS: Figural & -0.03 & 2.55 & $0.83^{* *}$ & $0.62^{* *}$ & $0.52^{* *}$ & $0.61^{* *}$ & $0.64^{* *}$ & $0.52^{* *}$ & & & & \\
\hline (8) BIS: Numerical & -0.00 & 3.12 & $0.84^{* *}$ & $0.69^{* *}$ & $0.56^{* *}$ & $0.46^{* *}$ & $0.69^{* *}$ & $0.44^{* *}$ & $0.55^{* *}$ & & & \\
\hline (9) Know: General & 0.02 & 1.77 & 0.10 & -0.12 & -0.01 & $0.20^{*}$ & $0.21^{*}$ & 0.11 & 0.14 & 0.01 & & \\
\hline (10) Know: Dec. Sys. t1 & 1.81 & 0.44 & $0.24^{* *}$ & 0.08 & 0.06 & 0.07 & $0.46^{* *}$ & $0.18^{*}$ & $0.18^{*}$ & $0.23^{* *}$ & $0.25^{* *}$ & \\
\hline (11) Know: Dec. Act. t1 & 5.69 & 1.73 & -0.00 & 0.04 & $-0.18^{*}$ & 0.07 & 0.06 & -0.08 & 0.01 & 0.05 & $0.21^{*}$ & 0.11 \\
\hline (12) Know: Pro. Act. t1 & 11.15 & 3.47 & 0.10 & 0.07 & 0.08 & 0.00 & 0.13 & 0.04 & 0.04 & 0.16 & 0.12 & 0.15 \\
\hline (13) Know: Spec. Tot. t1 & 72.75 & 13.07 & $0.25^{* *}$ & 0.10 & 0.04 & 0.10 & $0.46^{* *}$ & $0.18^{*}$ & $0.18^{*}$ & $0.24^{* *}$ & $0.30^{* *}$ & $0.93^{* *}$ \\
\hline (14) Know: Dec. Sys. t2 & 1.87 & 0.40 & $0.30 * *$ & 0.13 & 0.13 & 0.06 & $0.53^{* *}$ & $0.21^{*}$ & $0.21 *$ & $0.31^{* *}$ & $0.25^{* *}$ & $0.83^{* *}$ \\
\hline (15) Know: Dec. Act. t2 & 6.94 & 1.82 & 0.16 & 0.15 & -0.01 & 0.03 & $0.29^{* *}$ & 0.06 & 0.15 & $0.18^{*}$ & 0.15 & $0.27^{* *}$ \\
\hline (16) Know: Pro. Act. t2 & 11.83 & 3.41 & 0.07 & 0.06 & 0.08 & -0.07 & 0.13 & -0.05 & 0.08 & 0.13 & 0.14 & $0.17^{*}$ \\
\hline (17) Know: Spec. Tot. t2 & 76.84 & 12.37 & $0.32 * *$ & $0.18^{*}$ & 0.12 & 0.05 & $0.55^{* *}$ & $0.19 *$ & $0.24 * *$ & $0.35^{* *}$ & $0.28^{* *}$ & $0.80^{* *}$ \\
\hline (18) CPS & 138.00 & 72.58 & $0.22^{*}$ & 0.08 & -0.03 & $0.22^{*}$ & $0.34^{* *}$ & 0.11 & 0.16 & $0.25^{* *}$ & $0.36^{* *}$ & $0.43^{* *}$ \\
\hline (19) Gender & 1.41 & 0.49 & -0.04 & 0.04 & 0.08 & -0.05 & -0.17 & 0.15 & -0.04 & -0.17 & $-0.42^{* *}$ & $-0.32^{* *}$ \\
\hline (20) Age & 17.55 & 0.67 & $-0.21^{*}$ & $-0.20^{*}$ & -0.12 & -0.08 & $-0.19^{*}$ & $-0.18^{*}$ & -0.16 & -0.17 & 0.09 & $-0.25^{* *}$ \\
\hline
\end{tabular}

TABLE 1 | Continued

\begin{tabular}{|c|c|c|c|c|c|c|c|c|c|c|c|}
\hline Variable & $M$ & $S D$ & 11 & 12 & 13 & 14 & 15 & 16 & 17 & 18 & 19 \\
\hline (11) Know: Dec. Act. t1 & 5.69 & 1.73 & & & & & & & & & \\
\hline (12) Know: Pro. Act. t1 & 11.15 & 3.47 & 0.16 & & & & & & & & \\
\hline (13) Know: Spec. Tot. t1 & 72.75 & 13.07 & $0.28^{* *}$ & $0.41^{* *}$ & & & & & & & \\
\hline (14) Know: Dec. Sys. t2 & 1.87 & 0.40 & 0.07 & 0.07 & $0.75^{* *}$ & & & & & & \\
\hline (15) Know: Dec. Act. t2 & 6.94 & 1.82 & $0.49^{* *}$ & $0.18^{*}$ & $0.34^{* *}$ & $0.24^{* *}$ & & & & & \\
\hline (16) Know: Pro. Act. t2 & 11.83 & 3.41 & $0.17^{*}$ & $0.54^{* *}$ & $0.30^{* *}$ & $0.17^{*}$ & 0.14 & & & & \\
\hline (17) Know: Spec. Tot. t2 & 76.84 & 12.37 & $0.18^{*}$ & $0.22^{*}$ & $0.79^{* *}$ & $0.94^{* *}$ & $0.38^{* *}$ & $0.41^{* *}$ & & & \\
\hline (18) CPS & 138.00 & 72.58 & $0.36^{* *}$ & $0.24^{* *}$ & $0.51^{* *}$ & $0.37^{* *}$ & $0.28^{* *}$ & $0.29^{* *}$ & $0.46^{* *}$ & & \\
\hline (19) Gender & 1.41 & 0.49 & -0.15 & -0.06 & $-0.33^{* *}$ & $-0.38^{* *}$ & -0.14 & -0.11 & $-0.38^{* *}$ & $-0.35^{* *}$ & \\
\hline (20) Age & 17.55 & 0.67 & -0.06 & 0.05 & $-0.21^{*}$ & $-0.19 *$ & $-0.22^{* *}$ & -0.02 & $-0.19^{*}$ & $-0.24^{* *}$ & -0.02 \\
\hline
\end{tabular}

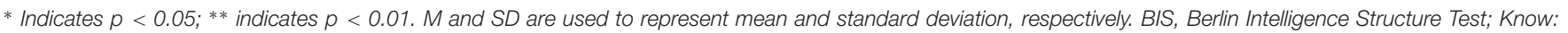

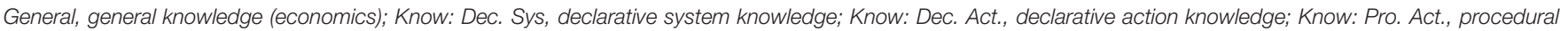

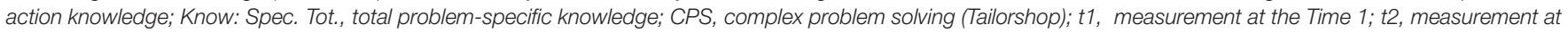
the Time 2.

TABLE 2 | Multiple regression of problem solving performance on the operation, content, and total scales of the BIS.

\begin{tabular}{|c|c|c|c|c|c|c|c|c|c|c|c|}
\hline & Speed & Mem. & Creat. & Reas. & $R^{2}$ adj & Verb. & Fig. & Num. & $R^{2}$ adj & g & $R^{2}$ \\
\hline Study 1: Tailorshop & $\begin{array}{r}-0.16 \\
(0.08)\end{array}$ & $\begin{array}{c}-0.16 \\
(-0.03)\end{array}$ & $\begin{array}{c}0.16 \\
(0.22 *)\end{array}$ & $\begin{array}{c}0.43^{*} \\
\left(0.34^{*}\right)\end{array}$ & $0.15^{*}$ & $\begin{array}{c}0.04 \\
(0.16)\end{array}$ & $\begin{array}{r}-0.01 \\
(0.11)\end{array}$ & $\begin{array}{c}0.22^{*} \\
\left(0.25^{*}\right)\end{array}$ & $0.04 *$ & $\begin{array}{c}0.22 \\
(0.22)\end{array}$ & 0.05 \\
\hline Study 2: FSYS & $\begin{array}{c}0.02 \\
\left(0.19^{*}\right)\end{array}$ & - & - & $\begin{array}{c}0.33^{*} \\
\left(0.34^{*}\right)\end{array}$ & $0.10^{*}$ & $\begin{array}{r}-0.18 \\
(0.07)\end{array}$ & $\begin{array}{c}0.38^{*} \\
\left(0.37^{*}\right)\end{array}$ & $\begin{array}{c}0.17 \\
\left(0.27^{*}\right)\end{array}$ & $0.16^{*}$ & $\begin{array}{c}0.33^{*} \\
\left(0.33^{*}\right)\end{array}$ & $0.10^{*}$ \\
\hline
\end{tabular}

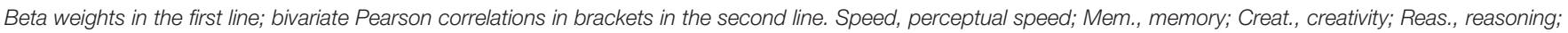
Verb, verbal intelligence; Fig., figural intelligence; Num, numerical intelligence. Values with * are significant at the $5 \%$ level.

numerical intelligence had a significant beta weight $(\beta=0.22$, $p=0.03)$. The proportion of variance accounted for by the operation scales was much higher than that accounted for by the content scales, despite the fact that the two groups of predictors consisted of the same items that had merely been aggregated in different ways. Building an overall aggregate for all BIS scales
(BIS-g) only accounted for five percent of the criterion variance $(r=0.22, p=0.01)^{4}$, compared to 15 percent with the four

${ }^{4}$ The correlation with CPS was slightly higher $(r=0.27)$ for a conventional g-score based on the factor scores of the first unrotated factor (Jensen and Wang, 1994), i.e., $7.3 \%$ of CPS variance was explained. 
operation scales. In line with the Brunswik symmetry principle (Wittmann, 1988; Wittmann and Süß, 1999), this comparison shows the benefit of differentiating intellectual abilities into multiple components using a multi-faceted model. Taking the cell level of the BIS ${ }^{5}$ into account, numerical reasoning was the best and thus likely the most symmetrical predictor of Tailorshop performance $(r=0.36, p<0.01){ }^{6}$ While the correlation between the numerical reasoning cell and the criterion was nearly the same as the correlation for reasoning, numerical reasoning was the better predictor given the substantially lower reliability of the cell score for numerical reasoning (Cronbach's $\alpha=0.77$ ) compared to reasoning (1-year stability, $r=0.90$, $p<0.01)$. Corrected for unreliability, the true correlation was $r=0.43$. In summary, aggregating repeated measures increases the reliability and thus also the validity of the CPS performance score. However, the correlations are lower than for minimally complex tasks even on the most symmetrical level $(r=0.58)$, as reported in Stadler et al.'s (2015) metaanalysis.

\section{Complex Problem Solving and Knowledge}

Four scales representing prior knowledge (time T1) were used as predictors of problem solving success in the regression analysis. These were the general economics test and the three categories of knowledge represented in the system-specific knowledge test: declarative system knowledge (measured with three subtests), declarative action knowledge (measured with the rules of thumb), and procedural action knowledge (measured using the systemstates task). General economics knowledge ( $\beta=0.21, p<0.01$; $\left.r_{\text {zero-order }}=0.36, p<0.01\right)$, declarative system knowledge $\left(\beta=0.33, p<0.01 ; r_{\text {zero-order }}=0.43, p<0.01\right)$, and declarative action knowledge $\left(\beta=0.26, p<0.01 ; r_{\text {zero-order }}=0.36, p<0.01\right)$ were significantly associated with problem solving performance, whereas procedural action knowledge was not $(\beta=0.13, p=0.07$; $r_{\text {zero-order }}=0.24, p<0.01$ ). The latter might be in part due to the low reliability of the test, which consisted of only six items. Together, general and system-specific knowledge accounted for 34 percent of the variance in CPS performance.

A significant increase in domain-specific knowledge from preto post-test was observed for every subscale. The strongest effect was for declarative action knowledge $(t=8.16, p<0.01, d=0.70)$, with smaller effects observed for declarative system knowledge $(t=2.86, p<0.01, d=0.25)$ and procedural action knowledge $(t=2.33, p<0.05, d=0.20)$. Pre-post correlations were 0.83 $(p<0.01)$ for declarative system knowledge, $0.49(p<0.01)$ for declarative action knowledge, and $0.54(p<0.01)$ for procedural action knowledge.

\section{An Integrative Path Model}

In a second step, we tested our theoretical model via path analysis. Reasoning and general economics knowledge were assumed to be correlated exogenous variables influencing the generation of hypotheses and the acquisition of system-specific

${ }^{5}$ According to the BIS, numerical reasoning is not a more specific ability but a performance based on reasoning and numerical intelligence (Jäger, 1982).

${ }^{6} \mathrm{The}$ correlation of CPS performance with figural reasoning was 0.26 , and 0.24 with verbal reasoning. knowledge during instruction and exploration, and thus also the amount of system-specific (prior) knowledge measured at time T1. We also assumed direct paths from reasoning, general economics knowledge and system-specific prior knowledge (T1) to control performance, and tested whether reasoning, domainspecific prior knowledge (T1) and problem-solving performance influence system-specific knowledge measured after controlling the system (T2). The resulting model is presented in Figure 4.

The path model reflects and extends the results above. Systemspecific prior knowledge (T1) was significantly influenced by the two correlated exogenous variables, indicating the importance of general domain knowledge, and especially of reasoning, for generating and testing hypotheses in the Tailorshop simulation. System-specific prior knowledge (T1) was influenced by learning processes during the instructions and, for a part of the sample, during system exploration. A total of $25.4 \%$ of the variance was explained by the two exogenous variables. General economics knowledge $(\beta=0.22, p<0.01)$ and system-specific prior knowledge (T1; $\beta=0.40, p<0.01$ ) also had direct effects on control performance. Reasoning ability, meanwhile, had no direct effect $(\beta=0.12, p=0.12)$, but a strong indirect effect on problem solving performance as mediated by prior knowledge. The total amount of explained variance in problem solving performance was $32 \%$. Finally, system-specific knowledge after controlling the system (T2) primarily depended on system-specific prior knowledge (T1; $\beta=0.65, p<0.01)$ as well as reasoning ( $\beta=0.25, p<0.01)$. Remarkably, while control performance and acquired system knowledge (T2) were substantially correlated $(r=0.46, p<0.01)$, the direct path from control performance to acquired system-specific knowledge (T2) was not significant ( $\beta=0.05, p=0.35)$. Overall, $68.6 \%$ of the variance was explained.

\section{Discussion}

Both intelligence and prior knowledge were shown to be important predictors of performance controlling a complex system. Some qualifications, however, must be made to this conclusion. First, it is not general intelligence that has predictive power for problem solving success in Tailorshop; instead and as expected, it is the primary factor reasoning, and more specifically numerical reasoning. This underscores the importance of finding the right level of symmetry between predictor and criterion in order to estimate their true relationship (Wittmann, 1988). Second, the correlation between reasoning and problem solving performance was mediated through prior knowledge; reasoning had no direct influence on problem solving performance. This finding is in line with the results of the meta-analysis by Schmidt et al. (1986; Schmidt, 1992), which showed that the relationship between intelligence and job performance is nearly completely mediated by task-related knowledge. This may indicate that persons with higher reasoning ability have used their ability to accumulate more domain knowledge in the past. The strong relationship between reasoning and general economics knowledge supports this account. An alternative explanation is that high reasoning ability helps people transfer their general domain knowledge to the specific situation, i.e., by deriving good hypotheses about the unknown system from their general 


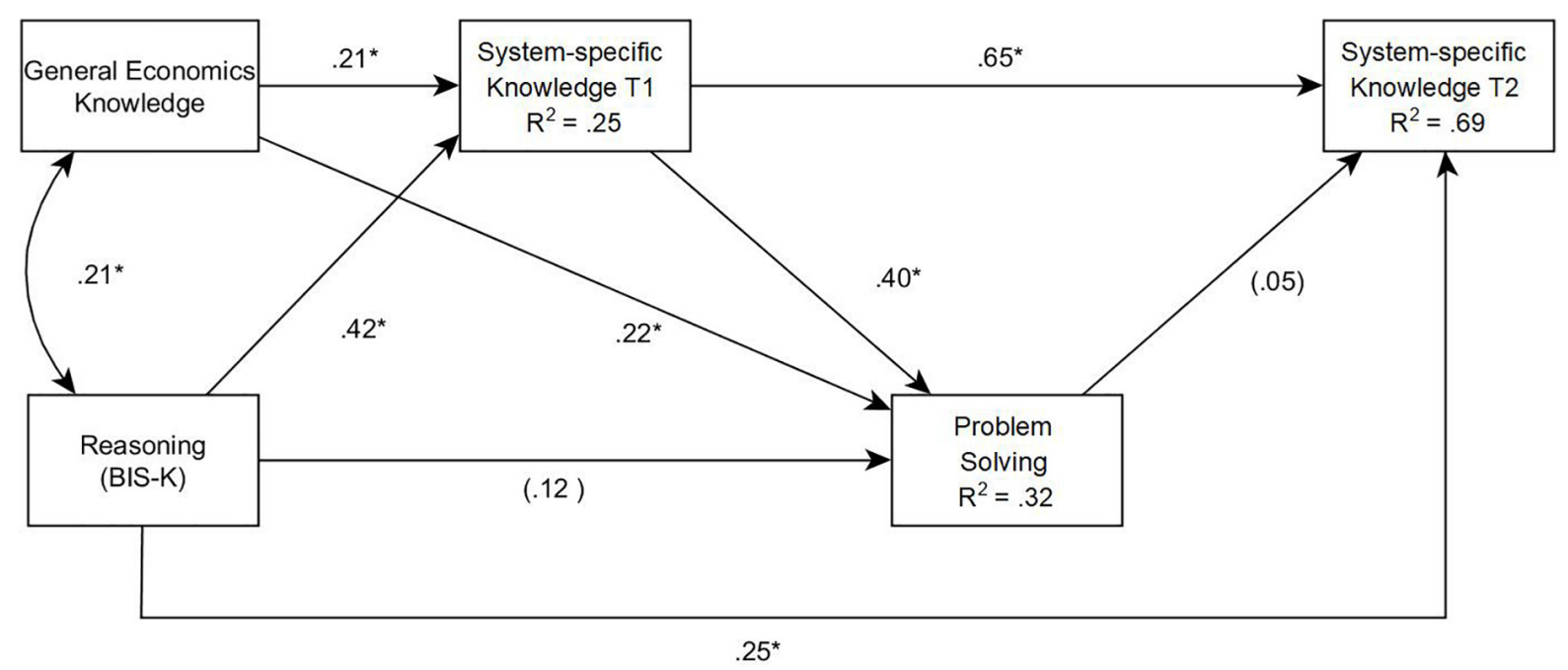

FIGURE 4 | Study 1: Path model for problem solving performance in Tailorshop with knowledge and reasoning as predictors. $\chi^{2}(1)=0.347, p=0.556$, Comparative Fit Index $(\mathrm{CFI})=1.000$. Values with * are significant at the $5 \%$ level.

theoretical knowledge about the corresponding domain. Systemspecific knowledge measured after controlling the system (T2) depends primarily on prior knowledge and reasoning. Therefore, controlling a complex system can be described as a knowledge acquisition process, providing evidence for Cattel's investment theory (Cattell, 1987). Assuming that the system has ecologically validity, this finding also indicates that system-specific knowledge measured after controlling a complex system is a powerful predictor of external criteria.

The study was limited to the computer-simulated system Tailorshop, a microworld mainly developed by psychologists. The scenario is realistic in that it captures many psychologically relevant features of complex real-life problems, but its ecological validity as a model for a real business environment is limited. For example, real company executives spend more than $80 \%$ of their time communicating orally (e.g., Mintzberg, 1973; Kotter, 1982), a demand which was not implemented in the simulation (see Süß, 1996).

A final but important qualification to the study's results concerns reasoning in the context of knowledge. System-specific knowledge was consistently the best single predictor of problem solving success in Tailorshop, while general domain knowledge in economics significantly predicted additional variance. Systemspecific knowledge was made up of two independent predictors, declarative system knowledge and declarative action knowledge. Our study found no evidence of the dissociation between verbalized knowledge and control performance repeatedly reported by Broadbent and colleagues (Broadbent et al., 1986; Berry and Broadbent, 1988; see Berry and Dienes, 1993). Tailorshop is a more complex and realistic system than those used by Broadbent and colleagues. Both factors might have strongly motivated people to make use of their preexisting knowledge, i.e., to formulate explicit hypotheses for controlling the system rather than following a trial-and-error approach that would result in the acquisition of implicit knowledge.

\section{STUDY 2}

The aim of the second study was to replicate and extend the findings presented so far. Study 2 differed from Study 1 in two important ways. First, we used the artificial world simulation FSYS (Wagener, 2001), which simulated a forestry company. Although FSYS has a rich semantic embedding and all the characteristics of complex problems, FSYS was developed with the aim of reducing the impact of previous knowledge of the simulated domain (i.e., general forestry knowledge) on problem solving performance. Therefore, FSYS can be classified as a CAS. Second, we included WMC as a further predictor. WMC is a more basic construct than reasoning and whether it is a better (i.e., more symmetrical) predictor of CPS performance than reasoning is an open question (see Zech et al., 2017). Thus, we were interested in whether one of the two constructs had incremental validity in predicting CPS performance beyond the other construct.

\section{Method \\ Participants}

One hundred fifty-nine students from the University of Magdeburg participated in the second study, which was originally conducted to evaluate a complex problem solving training (for details, see Kretzschmar and Süß, 2015), in 2010/2011.7 In the present analyses, we used the full sample but excluded all non-native German speakers $(n=7)$ due to the high language requirements of the intelligence test. The mean age was 23.99 years $(S D=4.43)$, and $50 \%$ were female. Participants received course credit for their participation or took part in a book raffle. Participants were informed about the content of the

\footnotetext{
${ }^{7}$ A subsample was used in Kretzschmar and Süß (2015) to evaluate a CPS training. However, none of the relations between CPS and the variables used in the present study have been previously examined (for details, see the data transparency table at https://osf.io/n2jvy). Therefore, all analyses and findings presented here are novel.
} 
study, the voluntary nature of participation and their ability to withdraw at any point, and that anonymity was guaranteed. All subjects provided informed consent.

\section{Materials \\ Problem solving}

We used version 2.0 of the microworld FSYS (Wagener, 2001). FSYS was developed on the basis of Dörner et al.'s (1983) theoretical framework for complex problem solving (Dörner, 1986). It is a microworld with 85 variables connected via linear, exponential, or logistic relations. The goal was to manage five independent forests in order to increase the company's value (i.e., planting and felling trees, fertilizing, pest control, etc.). Participants were first given an introduction to the program and had an opportunity to explore the system. They then managed the forest company for 50 simulated months. We used the company's total capital (i.e., an aggregated score of the five independent forests) at the end of the simulation as the performance indicator (SKAPKOR; see Wagener, 2001). Although FSYS simulates a forestry enterprise, the impact of prior knowledge was reduced by using abstract names for tree species, pests, fertilizer etc., and providing essential information about the artificial foresting world via an integrated information system. Previous studies have shown that FSYS has incremental predictive validity beyond general intelligence with regard to occupational (Wagener and Wittmann, 2002) and educational (Stadler et al., 2016) performance indicators. Figure 5 provides a screenshot of FSYS.

\section{Intelligence}

A short version of the BIS Test was used to assess intellectual abilities (Jäger et al., 1997). We specifically focused on reasoning and perceptual speed. Nine tasks were applied for each operation, balanced over the three content areas (i.e., figural, verbal, numerical; see Figure 1). These 18 tasks were administered according to the test manual. As in Study 1, the tasks were aggregated in order to build scales for each operation (i.e., reasoning, perceptual speed) or content (i.e., figural intelligence, verbal intelligence, numerical intelligence). An indicator for general intelligence was built by aggregating the 18 tasks in a balanced way, as described in the test handbook. Please note that the reliability of the two operative scales was lower than in Study 1; the construct validity of the three content scales and the measure of general intelligence were also reduced because no memory or creativity tasks were used. This limits the interpretability of the BIS content scales and the comparability of the results of the two studies.

\section{Working memory}

Working memory capacity was assessed with three tasks from the computerized test battery by Oberauer et al. (2003). The numerical memory updating (adaptive) and reading span (non-adaptive) tasks measured the simultaneous storage and processing functions of working memory, whereas the dot span task (also named spatial coordination; adaptive) primarily measured the coordination function. Moreover, each content category (i.e., figural, verbal, numerical) was represented by one task. A global score for WMC was calculated by aggregating the three equally weighted total task scores.

\section{Knowledge}

A questionnaire to assess general forestry knowledge as a measure of preexisting domain knowledge was developed for the purpose of this study ${ }^{8}$. It covered forestry knowledge in the subdomains of tree species, soils, nutrients, damage to a forest, and silviculture. An example question was: "Which tree is not a conifer?" The 22 multiple-choice items were scored dichotomously. Four items were excluded due to poor psychometric properties (i.e., a low item-total correlation). The remaining 18 items were aggregated to form a global sum score.

To assess system-specific knowledge about FSYS, we used Wagener's (2001) knowledge test about the microworld. The 11 multiple-choice items addressed system and action knowledge across all relevant areas of FSYS. For example: "A forest is infested by vermin XY. Which procedure would you apply?” In order to limit the number of questions, we did not differentiate between different types of knowledge. Therefore, we used a sum score as a global indicator of system-specific knowledge.

\section{Procedure}

Participants took part in two sessions each lasting about $2.5 \mathrm{~h}$. All testing was done in groups of up to 20 persons at the university computer lab. The first session comprised tests of intelligence and WMC. In the second session, participants completed tests of general forestry knowledge, complex problem solving, and system-specific knowledge. In contrast to Study 1, system-specific knowledge was assessed only once, after participants had worked with the CPS scenario (similar to Wagener, 2001). As the study was originally designed as an experimental training study (see Kretzschmar and Süß, 2015), the procedure differed slightly between the two experimental groups. About half of the participants completed the second session the day after the first session. The other half participated in a CPS training in between and completed the second session about 1 week after the first session.

\section{Results}

We will first present results for individual groups of predictors of CPS performance before integrating the results into a combined path model. Due to the original study design (i.e., exclusion criteria for the training, dropout from the first session to the second), up to $24 \%$ of the data for the knowledge tests and the CPS scenario were missing. We used the full information maximum likelihood (FIML) procedure to account for missing data. The smallest sample size in the analyses of individual groups of predictors was 116 . The data are publicly available via the Open Science Framework ${ }^{9}$. See Table 3 for descriptive statistics and the full correlation matrix.

\footnotetext{
${ }^{8}$ We would like to thank Clemens Leutner for professional advice in developing the questionnaire.

${ }^{9}$ https://osf.io/n2jvy
} 


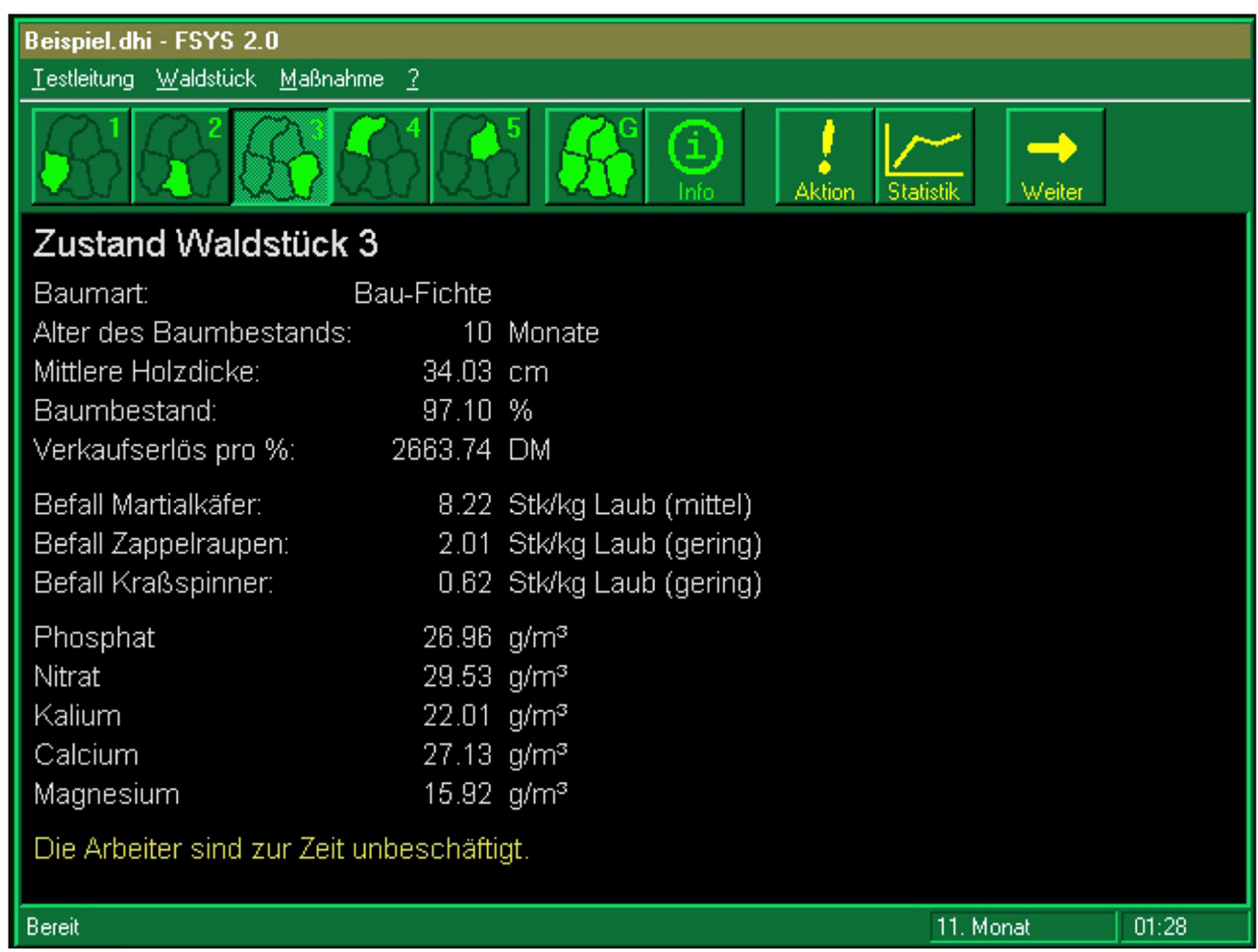

FIGURE 5 | Screenshot of the exploration phase of FSYS system as applied in Study 2.

TABLE 3 | Study 2: Means, standard deviations, and correlations.

\begin{tabular}{|c|c|c|c|c|c|c|c|c|c|c|c|c|c|}
\hline Variable & $M$ & $S D$ & 1 & 2 & 3 & 4 & 5 & 6 & 7 & 8 & 9 & 10 & 11 \\
\hline (1) BIS: g & 0.04 & 0.50 & & & & & & & & & & & \\
\hline (2) BIS: Speed & 0.04 & 0.60 & $0.82^{* *}$ & & & & & & & & & & \\
\hline (3) BIS: Reasoning & 0.04 & 0.57 & $0.88^{* *}$ & $0.47^{* *}$ & & & & & & & & & \\
\hline (4) BIS: Verbal & 0.08 & 0.60 & $0.71^{* *}$ & $0.69^{* *}$ & $0.60^{* *}$ & & & & & & & & \\
\hline (5) BIS: Figural & 0.02 & 0.62 & $0.84^{* *}$ & $0.69^{* *}$ & $0.71^{* *}$ & $0.47^{* *}$ & & & & & & & \\
\hline (6) BIS: Numerical & 0.01 & 0.69 & $0.78^{* *}$ & $0.67^{* *}$ & $0.68^{* *}$ & $0.35^{* *}$ & $0.46^{* *}$ & & & & & & \\
\hline (7) WMC & 0.12 & 2.10 & $0.55^{* *}$ & $0.41^{* *}$ & $0.52^{* *}$ & $0.33^{* *}$ & $0.45^{* *}$ & $0.48^{* *}$ & & & & & \\
\hline (8) Know: General & 8.35 & 2.74 & 0.08 & 0.00 & 0.13 & 0.04 & 0.03 & 0.09 & 0.02 & & & & \\
\hline (9) Know: Specific & 5.32 & 1.94 & $0.36^{* *}$ & 0.17 & $0.41^{* *}$ & $0.20^{*}$ & $0.35^{* *}$ & $0.23^{*}$ & $0.22^{*}$ & $0.19^{*}$ & & & \\
\hline (10) CPS & 57.59 & 22.51 & $0.33^{* *}$ & $0.19 *$ & $0.34^{* *}$ & 0.07 & $0.37^{* *}$ & $0.27^{* *}$ & $0.32^{* *}$ & 0.16 & $0.51^{* *}$ & & \\
\hline (11) Age & 23.99 & 4.43 & $-0.34^{* *}$ & $-0.21^{* *}$ & $-0.34^{* *}$ & $-0.23^{* *}$ & $-0.36^{* *}$ & $-0.17^{*}$ & $-0.31^{* *}$ & $0.24^{*}$ & -0.17 & $-0.21^{*}$ & \\
\hline (12) Gender & 0.50 & 0.50 & $-0.17^{*}$ & -0.05 & $-0.20^{*}$ & 0.13 & -0.09 & $-0.35^{* *}$ & -0.06 & -0.18 & $-0.20^{*}$ & -0.10 & -0.08 \\
\hline
\end{tabular}

* Indicates $p<0.05$; ** indicates $p<0.01 . \mathrm{M}$ and SD are used to represent mean and standard deviation, respectively. BIS, Berlin Intelligence Structure Test; WMC, working memory capacity; Know: General, general forestry knowledge; Know: Specific, system-specific knowledge; CPS, complex problem solving performance (FSYS).

\section{Complex Problem Solving, Intelligence, and Working Memory}

The results of two multivariate regressions of FSYS performance scores on the BIS operative and content scales, respectively, are summarized in Table 2 (lower half, correlations in brackets).
The results for operation abilities are similar to those from the first study, with reasoning the only significant predictor $(\beta=0.33, p<0.01)$. However, figural intelligence was the only statistically significant predictor among the content scales $(\beta=0.38, p<0.01)$. This seems plausible given that 
FSYS displays important information graphically rather than numerically (e.g., diagrams showing the forestry company's development). However, a large amount of information is also presented numerically, meaning that numerical reasoning should exert an influence as well. Taking the cell level of the BIS into consideration: Numerical reasoning (Cronbach's $\alpha=0.66)$ became similarly strongly associated with FSYS control performance $(r=0.37, p<0.01$; corrected for unreliability $r=0.46$ ) as figural reasoning (Cronbach's $\alpha=0.72$; $r=0.36, p<0.01$; corrected for unreliability $r=0.42)$. Verbal reasoning (Cronbach's $\alpha=0.51$ ) remained unassociated with FSYS performance $(r=0.02, p=0.82)$. In contrast to Study 1 , the content scales accounted for a slightly larger share of the variance in FSYS (16\%) than the operation scales (10\%). General intelligence (BIS-g) had a.33 $(p<0.01)$ correlation with problem solving performance.

Next, we compared the impact of reasoning and WMC as predictors of success in FSYS. Both predictors exhibited an almost equal and statistically significant zero-order correlation $\left(r_{\mathrm{BIS}-\mathrm{R} . \mathrm{FSYS}}=0.34, p<0.01 ; r_{\mathrm{WMC} \text {.FSYS }}=0.32, p<0.01\right)$. In hierarchical regressions, each explained a similar but nonsignificant amount of incremental variance over and above the other predictor $\left(\Delta R_{\text {BIS.K }}^{2}=0.02 ; \Delta R^{2}\right.$ WMC $\left.=0.02\right)$. The total explained variance was $12.2 \%$ (adjusted). In summary, working memory did not increase the statistical significance of the multiple correlation when entered as a second predictor.

\section{Complex Problem Solving and Knowledge}

General forestry knowledge was not significantly correlated with FSYS performance $(r=0.16, p=0.09)$. Thus, the (non-)impact of prior domain knowledge in FSYS was similar as in previous studies ( $r=0.13$; Wagener, 2001), emphasizing how the impact of prior knowledge depends on the specific type of microworld (i.e., CRS in Study 1 vs. CAS in Study 2). The correlation between system-specific knowledge (measured after working on FSYS) and FSYS performance was $r=0.51(p<0.01)$.

\section{An Integrative Path Model}

In line with our assumptions about the relations among the predictor and criterion variables and building upon the results of the first study, we constructed a path model to integrate our findings. Perceptual speed from the BIS Test was excluded from the analyses because it was not significantly associated with any endogenous variable when controlling for reasoning. Prior general forestry knowledge was also omitted from the path model for the same reason.

In the first model (Figure 6, Model A), working memory had a direct influence on reasoning but not on FSYS control performance and system-specific knowledge. In this model $\left[\chi^{2}(2)=4.538, p=0.10, \mathrm{CFI}=0.977\right.$, SRMR $\left.=0.038\right]$, control performance $(\beta=0.34, p<0.01)$ and acquired system-specific knowledge about the microworld FSYS $(\beta=0.26, p<0.01)$ were significantly influenced by reasoning. The total amount of explained variance for control performance and system-specific knowledge were $11 \%$ and $32 \%$, respectively.

In a second (fully saturated) model (Figure 6, Model B: dashed lines and coefficients in brackets), direct paths from working memory to FSYS control performance and system-specific knowledge were added. In this model, working memory had a small but non-significant direct effect on control performance $(\beta=0.20, p=0.09)$, i.e., the effect of working memory is primarily based on its shared variance with reasoning. Furthermore, WMC functioned as a suppressor when it came to predicting systemspecific knowledge. In other words, despite the positive zero order correlation between the two variables (see above), the direct path from WMC to system-specific knowledge was negative $(\beta=-0.13, p=0.19)$, while the impact of reasoning on systemspecific knowledge slightly increased $(\beta=0.33, p<0.01)$. On the other hand, the path from working memory to system-specific knowledge was statistically non-significant, and the explained variance in system-specific knowledge did not significantly increase $\left[\Delta R^{2}=0.012, F(1,148)=2.663, p=0.46\right]$.

\section{Discussion}

The general findings of Study 1 with regard to the impact of intelligence on CPS performance could be replicated in Study 2. However, as Study 2 was conducted with a different microworld with different cognitive demands (e.g., less relevance of prior knowledge), the results differed somewhat compared to those of Study 1.

With regard to intelligence, reasoning was again the strongest and sole predictor of CPS performance. Because general intelligence (g) was operationalized substantially more narrowly than in Study 1, the results for reasoning and $g$ were comparable. These findings highlight the effect of the specific operationalization of intelligence selected. If intelligence is broadly operationalized, as proposed in the BIS (see Study 1), the general intelligence factor is not equivalent to reasoning (aka fluid intelligence; see also Carroll, 1993; McGrew, 2005; Horn, 2008) and different results for $\mathrm{g}$ and for reasoning in predicting CPS performance can be expected (see e.g., Süß, 1996). With regard to the content facet, FSYS shared the most variance with figural intelligence. However, the cell level of the BIS provided a more fine-grained picture: figural reasoning was just as highly correlated with FSYS performance as numerical reasoning. Although Study 1 and Study 2 must be compared with caution (i.e., due to different operationalizations of the BIS scales, see Figure 1, and limited BIS reliability on the cell level), it is clear that different CPS tests demand different cognitive abilities. At the same time, these findings highlight the importance of the Brunswik symmetry principle (Wittmann, 1988; Wittmann and Süß, 1999). A mismatch between predictor and criterion (e.g., figural reasoning and Tailorshop performance in Study 1; or numerical intelligence and FSYS performance in Study 2) substantially reduces the observed correlation (for another empirical demonstration in the context of CPS, see Kretzschmar et al., 2017). Ensuring that the operationalizations of the constructs are correctly matched provides an unbiased picture of the association across studies (Zech et al., 2017).

Working memory capacity was strongly related to reasoning and largely accounted for the same portion of variance in problem solving success as reasoning; it did not explain substantial variance over and above reasoning. These results complement the mixed pattern of previous findings, in which 


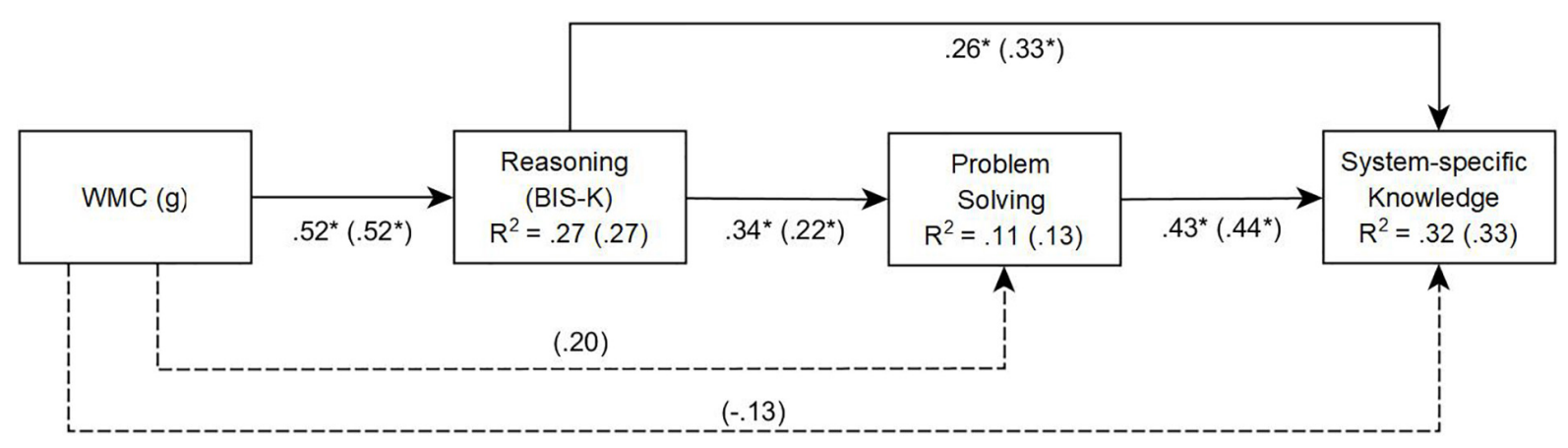

FIGURE 6 | Study 2: Path Model A for problem solving performance and system-specific knowledge in FSYS, predicted by reasoning and working memory capacity (WMC). Fit for model A (without dashed lines): $\chi^{2}(2)=4.538, p=0.10$, Comparative Fit Index (CFI) $=0.977$. Path model $B$ (saturated) with dashed lines and values in brackets. Values with * are significant at the $5 \%$ level.

working memory explained CPS variance above and beyond intelligence (Wittmann and Süß, 1999), was the only predictor of CPS variance when simultaneously considering figural reasoning (Bühner et al., 2008), but did not explain CPS variance above and beyond reasoning (Greiff et al., 2016). In our view, there is little unique criterion variance to explain because the predictors are highly correlated. Even small differences in operationalization or random fluctuations can make one or the other predictor dominate (for a different view, see Zech et al., 2017).

Preexisting knowledge (i.e., general forestry knowledge) did not contribute to problem solving success. This finding highlights the importance of the CPS measurement approach selected. Whereas Tailorshop was developed as a complex real lifeoriented simulation in which prior domain knowledge plays a substantial role, FSYS was developed with the aim of reducing the influence of prior knowledge (Wagener, 2001). Therefore, in addition to the distinction between microworlds and MCS, the differential impact of prior knowledge in terms of semantic embedding has to be considered when examining the validity of CPS (e.g., the effects might differ for CRS vs. CAS, as in the present study). It should be noted that in Stadler et al.'s (2015) meta-analysis, a study featuring FSYS (in which prior knowledge has no impact) and a study involving a virtual chemistry laboratory (in which prior knowledge has an effect; see Scherer and Tiemann, 2014) were both classified as single complex system studies. As a substantial portion of the variance in CPS performance in semantically embedded microworlds can be attributed to prior knowledge, the question arises as to whether a more fine-grained classification of the CPS measures in Stadler et al.'s (2015) meta-analysis would have resulted in different findings. In summary, the heterogeneity of different CPS measurements makes it difficult to compare studies or conduct meta-analyses (some would say impossible, see Kluwe et al., 1991).

\section{GENERAL DISCUSSION}

The presented studies had two main goals. First, we wanted to investigate the predictive validity of differentiated cognitive constructs for control performance in complex systems. Second, we were interested in how preexisting general knowledge and system-specific prior knowledge contribute to successful system control.

Both studies clearly demonstrate that intelligence plays an important role in control performance in complex systems. This is in contrast to former claims in early CPS research that problem solving success in complex, dynamic, partially intransparent systems is not at all correlated with intelligence test scores (e.g., Kluwe et al., 1991). Our results point to several explanations for prior failures to find positive correlations. First, previous studies used only a single problem solving trial, meaning that the performance criterion presumably was not satisfactorily reliable. Second, several previous studies did not differentiate between different aspects of intelligence, but used a measure of general intelligence. In our studies, however, general intelligence $(\mathrm{g})$ as conceptualized in the BIS and operationalized with the BIS Test was not a good predictor of control performance. Instead and as was expected, the second-order construct of reasoning, and more specifically numerical reasoning, had the strongest relationship with success in the complex real-world oriented system (Tailorshop), while figural and numerical reasoning had the strongest relationship with success in the complex artificial world problem (FSYS). However, whether $\mathrm{g}$ and reasoning are distinguishable from each other (Carroll, 1993), and thus also whether the two differ in predicting CPS performance, depends on the level of generality, i.e., the broadness of the operationalization of g.

Our results are in line with the first Berlin study (Süß et al., 1993a,b) and several other studies using the Tailorshop system and other CRSs focusing on ecological validity (e.g., Wittmann and Süß, 1999; Kersting, 2001; Leutner, 2002; Rigas et al., 2002; Ryan, 2006; Danner et al., 2011), and were confirmed in Stadler et al.'s (2015) meta-analysis.

\section{Is There Evidence for a New Construct 'Complex Problem Solving Ability'?}

The two presented studies, however, are limited to one microworld each, and do not answer broader questions 
regarding generalizability. In particular, the convergent validity of microworlds was not addressed, but this question is essential for postulating complex problem solving ability as a new ability construct.

The following criteria must be considered in justifying a new ability construct (cf., Süß, 1996, 1999): (1) temporal stability, (2) a high degree of generality (i.e., the construct can be operationalized across different tasks, showing convergent validity), (3) partial autonomy in the nomological network of established constructs (i.e., the shared performance variance in different tasks cannot be explained by well-established constructs), and (4) evidence for incremental criterion validity compared to established constructs. In this section, we briefly review the empirical results regarding the existence of a unique CPS construct. We focus on CPS research utilizing CRS (i.e., microworlds with semantic embeddings ${ }^{10}$.

The 1-year stability of CRS performance in the Berlin study (see Süß, 1996) was $r=0.49$, which is substantial, but much lower than that for the intelligence constructs. The temporal stability of the BIS scales ranged from 0.65 for creativity to 0.90 for reasoning. In addition, the time-stable performance variance was explained completely by intelligence and prior knowledge (Süß, 1996). To the best of our knowledge, no results on temporal stability for other CRS and temporal stability for aggregated scores based on different CRS are currently available.

Wittmann et al., (1996; Wittmann and Süß, 1999; Wittmann and Hattrup, 2004) investigated the convergent validity of CRS. Wittmann et al. (1996) applied three different CRS (PowerPlant, Tailorshop, and Learn!), the BIS Test and domain-specific knowledge tests for each system to a sample of university students. The correlations of the CRS were significant but rather small (0.22-0.38), indicating low convergent validity ${ }^{11}$. However, because the reliability of each CRS was substantially higher than their intercorrelations, substantial system-specific variance has to be assumed. Performance on each of the three systems was predicted by reasoning and domain-specific prior knowledge to a substantial degree. In a structural equation model with a nestedfactor BIS model (Schmid and Leiman, 1957; Gustafsson and Balke, 1993) as predictor, the CPS g-factor with two performance indicators for each of the three systems (i.e., the CPS ability construct) was predicted by general intelligence $(\beta=0.54)$, creativity $(0.25)$ and reasoning (0.76), whereas perceptual speed and memory did not contribute to prediction (Süß, 2001) $)^{12}$. In this model, reasoning, though orthogonal to general intelligence,

\footnotetext{
${ }^{10}$ For a review focusing on CPS research applying the minimally complex systems (MCS) approach, see Kretzschmar and Süß (2015).

${ }^{11}$ In the study of Ryan (2006) with 298 University students the intercorrelations of three scenarios, Furniture Factory (FF), Taylorshop (T) and FSYS (F), were also rather small but significant $\left(r_{\mathrm{FF}, \mathrm{T}}=0.30, r_{\mathrm{FF}, \mathrm{F}}=0.27, r_{\mathrm{T}, \mathrm{F}}=0.10\right.$; Stankov, 2017).

${ }^{12}$ The structural equation model by Süß (2001) is copied in Wittmann and Hattrup (2004) as Figure 6. This model was built in two steps: First, BIS and CPS-g were modeled separately. Specific CPS factors for the three systems were not modeled because only two indicators were available for each system. Instead, the errors of the two indicators in each system were allowed to correlated as system-specific variance. Second, the five BIS factors ( $\mathrm{g}$ and the four operative abilities) were used to predict CPS-g. Fit statistics for the final model are not valid because the loadings of both measurement models were optimized in the first step.
}

was the strongest predictor of the complex problem solving ability factor. Almost all of the variance could be explained by the BIS, putting the autonomy of the CPS construct into question.

In sum, there is no evidence for a new ability construct based on CRSs. This, however, does not mean that this kind of research cannot provide important new insights into CPS processes (see Süß, 1999), and that CPS performance cannot predict real-life performance beyond psychometric intelligence measures to a certain extent (e.g., Kersting, 2001; Danner et al., 2011).

Kersting (2001) predicted police officers' job performance over 20 months on the basis of intelligence (short scales for reasoning and general intelligence from the BIS Test), CPS performance (two simulations, including Tailorshop), and acquired system-specific knowledge (measured after controlling the system). In a commonality analysis (Kerlinger and Pedhazur, 1973), $24.9 \%$ of job performance variance was explained. The strongest specific predictor was intelligence (7.3\%; reasoning and general intelligence at about the same level); CPS performance and system-specific knowledge explained 3.9 and $3.0 \%$ of the overall criterion, respectively. The largest share of the variance was confounded variance between intelligence and system-specific knowledge (24.9\%). In comparison to our first study, both intelligence scales had reduced predictive validity due to lower reliabilities. However, this study shows that exploring and controlling CRS must be considered a learning process. Acquired system knowledge represents invested intelligence (i.e., crystallized intelligence) and was a small but additional predictor of real-life performance beyond intelligence. This provides that ecological-valid complex systems can additionally predict external criteria, and are useful learning and training tools for acquiring domain-specific knowledge.

\section{PART II: REVIEW AND CRITIQUE OF THE MINIMALLY COMPLEX SYSTEM (MCS) APPROACH}

The research presented and discussed in the first part of the paper focuses on CRSs. From the beginning, CRS research was criticized for numerous reasons, including the lack of a formal description of the system, the lack of an optimal solution as an evaluation criterion for subjects' behavior and performance, the uncontrolled influence of prior knowledge, low or unknown reliability of the scores, and low or even non-existent convergent validity and predictive validity with respect to relevant external criteria (for summaries, see e.g., Funke, 1995; Süß, 1996; Kluge, 2008a). Therefore, the MCS approach (Greiff et al., 2012) was developed to overcome the limitations of former microworlds. The MCS approach is remarkably prominent in recent CPS research, which may be a consequence of the higher reliability and validity such systems are assumed to have in comparison to CRS (e.g., Greiff et al., 2015b). Consequently, some might argue that research on CPS performance based on CRS, as presented in the first part of the paper, is less reliable and informative. However, whether the MCS approach is really a superior alternative to 
studying problem solving in complex situations remains up for debate.

The MCS approach updates and further develops ideas that have been present since the beginning of CPS research. Funke (1993) suggested artificial dynamic systems as a research tool based on systems of linear equations. Buchner and Funke (1993) proposed the theory of finite state automata as a tool for developing CPS tasks. Applying this, Kröner (2001; Kröner et al., 2005), for example, implemented MultiFlux, which simulates a fictitious machine, within the finite-state framework. This idea was further developed into MCS, e.g., Genetics lab (Sonnleitner et al., 2012) and MicroDYN (Greiff et al., 2012). Generally, about 9-12 artificial world tasks, tiny systems with up to three exogeneous and three endogenous variables each, are applied in three phases: (1) free system exploration, (2) knowledge acquisition (i.e., assessment of acquired system knowledge), and (3) knowledge application (i.e., assessment of action knowledge). The required testing time is less than $5 \mathrm{~min}$ for each minimal system. Each system provides three scores, one for each of the above-mentioned phases, which are then used to form three corresponding knowledge scales. According to our knowledge taxonomy, Phase 2 measures declarative system knowledge (i.e., relations between variables), while Phase 3 measures procedural action knowledge (i.e., system interventions in order to achieve a given goal). The items in these two subtests are similar to the items in the arrows task and the system-states task of the Tailorshop knowledge test. Whereas each item in the MCS scales refers to a different minimal system, all items in the Tailorshop knowledge test refer to the same system. Nevertheless, the MCS tasks are very similar to each other and implement only a small number of CPS characteristics, giving the subtests high internal consistencies. Specifically, all minimal systems can be fully explored with the simple strategy "vary one thing at a time" (VOTAT; e.g., Vollmeyer et al., 1996) or the closely related strategy "vary one or none at a time" (Beckmann and Goode, 2014; for additional distinctions see Lotz et al., 2017). No special training is necessary to learn these strategies. Instead, they can be learned by instruction or examples of correct and incorrect applications. On the other hand, these strategies are clearly not sufficient for exploring CRS, i.e., systems with many exogeneous variables, indirect and side effects, delayed effects, and eigendynamics, especially if the time for the task is limited or in real-time simulations (e.g., Bremer's fire-fighter; Rigas et al., 2002). For the latter, the quality of one's hypotheses, which is based on domain knowledge, is a necessary prerequisite for successfully exploring the system. In summary, the features of MCS measurements outlined here, along with further criticisms of this approach (e.g., Funke, 2014; Scherer, 2015; Schoppek and Fischer, 2015; Dörner and Funke, 2017; Funke et al., 2017; Kretzschmar, 2017), substantially narrow the validity of the MCS approach as an indicator of CPS.

On the other hand, the relevance of the MCS approach is shown by many studies that have modeled the internal structure of MCS tasks (e.g., Greiff et al., 2012; Sonnleitner et al., 2012), provided evidence that performance variance cannot be sufficiently explained by reasoning (e.g., Wüstenberg et al.,
2012; Sonnleitner et al., 2013; Kretzschmar et al., 2016), found strong convergent validity as well as a lower correlation with a CRS (i.e., Tailorshop; Greiff et al., 2015b; for a different view, see Kretzschmar, 2017), and demonstrated incremental validity in predicting school grades beyond reasoning (e.g., Greiff et al., 2013b; Sonnleitner et al., 2013; for different results, see Kretzschmar et al., 2016; Lotz et al., 2016) and beyond a CRS task (Greiff et al., 2015b). MCS have been proposed as a tool for assessing 21st Century skills (Greiff et al., 2014) and were applied in the international large-scale study PISA to assess general problem-solving skills (OECD, 2014). They have further been proposed as training tools and evaluation instruments for these skills (e.g., Greiff et al., 2013a; Herde et al., 2016). This begs the question: how strong is the empirical evidence? Are these far-reaching conclusions and recommendations justified?

Studies provide support for the psychometric quality, especially the reliability, of the MCS approach, although scale building and some statistics have been criticized (Funke et al., 2017; Kretzschmar, 2017). Only one study so far has attempted to compare MCS and CRS. In it, Greiff et al. (2015b) argued that MCS had a higher validity than Tailorshop in predicting school grades. The knowledge scales assessed after exploring the system were used as predictors for the MCS. However, systemspecific knowledge for Tailorshop after controlling the system was not assessed (Kretzschmar, 2017). Instead, control performance was used as a predictor of school grades. Control performance, however, is not a valid measure of acquired knowledge, as demonstrated in our first study. For this, additional tests are needed after controlling the system, conducted in both studies in this paper.

Minimally complex systems research also only sparingly addresses questions of construct validity related to the measures and the conclusions (i.e., generalizability; see Kretzschmar, 2015). This concerns the operationalization of CPS characteristics (i.e., the construct validity of the MCS), which was addressed in more detail above. However, limitations also exist concerning the choice of the additional instruments applied in validation studies. The construct validity of many instruments is considerably limited, causing results to be overgeneralized (cf., Shadish et al., 2002). For example, operationalizing reasoning (i.e., fluid intelligence) with a single task (e.g., the Raven matrices; Wüstenberg et al., 2012; Greiff and Fischer, 2013) is not sufficient. Construct validity is also restricted if only one task is used to measure WMC (e.g., Bühner et al., 2008; Schweizer et al., 2013). Since Spearman's (1904), work we know that task-specific variance can be reduced only through heterogeneous operationalizations of the intended constructs. The two studies reported in this paper show how strongly the relationship between intelligence and CPS performance varies depending on the generality level of the intelligence construct (see also Kretzschmar et al., 2017). The symmetry problem was demonstrated here for the BIS, but is also evident with regard to other hierarchical intelligence models, e.g., the Three Stratum theory (Carroll, 1993, 2005), the extended GfGc theory (Horn and Blankson, 2005; Horn, 2008), and the Cattell-Horn-Carroll theory (CHC theory; McGrew, 2005, 2009). 
Süß and Beauducel (2011), therefore, classified every task of the most frequently used tests into the BIS, the three stratum theory, and the $\mathrm{CHC}$ theory to give a framework for this problem.

According to the BIS (Jäger, 1982), every intelligence task depends on at least two abilities (an operative and a content ability), i.e., every task relates to two different constructs. By extension, the interpretation in terms of only one ability is of limited validity due to unintended but reliable task-specific variance. It is either necessary to have several tasks for every construct and theory-based aggregation (Jäger, 1982, 1984) to reduce unintended variance, or the interpretation must be limited to a more specific conclusion (e.g., to numerical reasoning in our first study). The two studies presented here and many others show that these kinds of problems substantially influence the validity of conclusions in intelligence and problem solving research as well as in many other fields (Shadish et al., 2002).

In summary, the MCS approach provides solutions to psychometrics problems in CPS research, especially the reliability problem, but its validity as an indicator of CPS performance is substantially restricted. In our view, MCS are an interesting new class of problem-solving tasks, but provide few insights into complex real-world problem solving. Modifications of the MCS approach toward increased complexity (e.g., MicroFIN; Neubert et al., 2015; Kretzschmar et al., 2017) are a promising step in the right direction.

\section{Conclusion and Outlook}

The primary aim of CPS research with CRSs (e.g., Lohhausen; Dörner et al., 1983) is ecological validity, i.e., "the validity of the empirical results as psychological statements for the real world" (Fahrenberg, 2017). In the past, many systems were "ad hoc" constructions by psychologists that had not been sufficiently validated, but this need not be the case. What is needed is interdisciplinary research in the form of collaboration with experts in the simulated domains. For example, Dörner collaborated with a business expert to develop Tailorshop. Powerplant was developed by Wallach (1997) together with engineers from a coal-fired power plant near Saarbrücken (Germany). LEARN!, a complex management simulator with more than 2000 connected variables, was originally developed by an economics research group at the University of Mannheim (Germany) as a tool for testing economic theories (Milling, 1996; Größler et al., 2000; Maier and Größler, 2000). In the version applied by Wittmann et al. (1996), participants have to manage a high-technology company competing with three others simulated by the computer. ATC (Air Traffic Controller Test; Ackerman and Kanfer, 1993) and TRACON (Terminal Radar Air Control; Ackerman, 1992) are simplified versions of vocational training simulators for professional air traffic controllers. The Situational Awareness Real Time Assessment Tool (SARA-T) was developed to measure the situational awareness of air traffic controllers working in the NLR ATM Research Simulator (NARSIM; ten Have, 1993), a system also used in expert studies (Kraemer and Süß, 2015; Kraemer, 2018). Finally, technological developments (e.g., video clips, virtual worlds; Funke, 1998) have enabled the development of complex systems that are much more similar to real-world demands than ever before, an opportunity that should be capitalized upon in psychological research (see Dörner and Funke, 2017).

In this line of research, the ecological validity of the simulated real-world relationships is essential and must be ensured. In addition, domain-specific prior knowledge is necessary to generate hypotheses for system exploration and system control. Valid measures of the amount, type, and structure of domainspecific prior knowledge, the knowledge acquisition processes, and the acquired knowledge are necessary for understanding and measuring CPS behavior and performance. In light of all this, this line of research can help us to understand how people face the challenge of dealing with complexity and uncertainty, identify causes of failure, and detect successful strategies for reducing complexity during problem solving (e.g., Dörner, 1996; Dörner and Funke, 2017), a laborious and time-consuming but important field of research in complex decision making (cf., Gigerenzer and Gaissmaier, 2011). The research strategy of restricting complex problem solving tasks to MCS, however, leads into a cul-de-sac.

\section{ETHICS STATEMENT}

The studies were carried out in accordance with the ethical guidelines of the German Association of Psychology with informed consent from all subjects. Considering the time when the studies were conducted and the fact that the materials and procedures were not invasive, the studies were not approved by an ethical committee.

\section{AUTHOR CONTRIBUTIONS}

H-MS conceptualized the manuscript and conducted the first study. AK conducted the second study. H-MS and AK analyzed the data and drafted the manuscript in collaboration.

\section{FUNDING}

The first study was supported by a grant from the Free University of Berlin's Commission for Research Promotion (FNK) to the first author and A. O. Jäger. We further acknowledge support by the Deutsche Forschungsgemeinschaft and the University of Tübingen's Open Access Publishing Fund. In addition, this research project was supported by the Postdoc Academy of the Hector Research Institute of Education Sciences and Psychology, Tübingen, funded by the Baden-Württemberg Ministry of Science, Education and the Arts.

\section{ACKNOWLEDGMENTS}

We thank Klaus Oberauer for his helpful comments on the manuscript. 


\section{REFERENCES}

Ackerman, P. L. (1992). Predicting individual differences in complex skill acquisition: dynamics of ability determinants. J. Appl. Psychol. 77, 598-614. doi: 10.1037/0021-9010.77.5.598

Ackerman, P. L., and Kanfer, R. (1993). Integrating laboratory and field study for improving selection: development of a battery for predicting air traffic controller success. J. Appl. Psychol. 78, 413-432. doi: 10.1037/0021-9010.78. 3.413

Bainbridge, L. (1974). “Analysis of verbal protocols from a process control task," in The Human Operator in Process Control, eds E. Edwards and F. P. Lees (London: Taylor \& Francis), 146-158.

Barth, C. M., and Funke, J. (2010). Negative affective environments improve complex solving performance. Cogn. Emot. 24, 1259-1268. doi: 10.1080/ 02699930903223766

Beckmann, J. F., and Goode, N. (2014). The benefit of being naïve and knowing it: the unfavourable impact of perceived context familiarity on learning in complex problem solving tasks. Instr. Sci. 42, 271-290. doi: 10.1007/s11251-013-9280-7

Berry, D. C., and Broadbent, D. E. (1988). Interactive tasks and the implicit-explicit distinction. Br. J. Psychol. 79, 251-272. doi: 10.1111/j.2044-8295.1988.tb02286.x

Berry, D. C., and Dienes, Z. (1993). Implicit Learning. Theoretical and Empirical Issues. Hillsdale, MI: LEA.

Brehmer, B. (1986). "In one word: not from experience," in Judgment and Decision Making, eds H. R. Arkes and K. R. Hammond (Cambridge: Cambridge University Press), 705-720.

Broadbent, D. E., Fitzgerald, P., and Broadbent, M. H. P. (1986). Implicit and explicit knowledge in the control of complex systems. Br. J. Psychol. 77, 33-50. doi: 10.1111/j.2044-8295.1986.tb01979.x

Buchner, A., and Funke, J. (1993). Finite state automata: dynamic task environments in problem solving research. Q. J. Exp. Psychol. 46A, 83-118. doi: 10.1080/14640749308401068

Bühner, M., Kröner, S., and Ziegler, M. (2008). Working memory, visual-spatialintelligence and their relationship to problem-solving. Intelligence 36, 672-680. doi: $10.1016 /$ j.intell.2008.03.008

Carroll, J. B. (1993). Human Cognitive Abilities. A Survey of Factor-Analytic Studies. New York, NY: Cambridge University Press. doi: 10.1017/CBO97805115 71312

Carroll, J. B. (2005). "The three-stratum theory of cognitive abilities," in Contemporary Intellectual Assessment: Theories, Test, and Issues, 2nd Edn, eds D. P. Flanagan and P. L. Harrison (New York, NY: Guilford Press), 69-76.

Cattell, R. B. (1987). Intelligence: Its Structure, Growth, and Action. Amsterdam: Elsevier.

Ceci, S. J., and Liker, J. K. (1986). A day at the races: a study of IQ, expertise, and cognitive complexity. J. Exp. Psychol. Gen. 115, 255-266. doi: 10.1037/00963445.115.3.255

Chi, M. T. H., Glaser, R., and Farr, M. J. (1988). The Nature of Expertise. Hillsdale, NJ: Erlbaum.

Conway, A. R., Kane, M. J., and Engle, R. W. (2003). Working memory capacity and its relation to general intelligence. Trends Cogn. Sci. 7, 547-552. doi: $10.1016 /$ j.tics.2003.10.005

Csapó, B., and Molnár, G. (2017). Potential for assessing dynamic problemsolving at the beginning of higher education studies. Front. Psychol. 8:2022. doi: 10.3389/fpsyg.2017.02022

Danner, D., Hagemann, D., Holt, D. V., Hager, M., Schankin, A., Wüstenberg, S., et al. (2011). Measuring performance in dynamic decision making: reliability and validity of the Tailorshop simulation. J. Individ. Dif. 32, 225-233. doi: 10.1027/1614-0001/a000055

Deutsche Gesellschaft für Personalwesen [DGP] (1986). Differentieller Kenntnistest (DKT). Subtest Wirtschaft [Differential Test of Knowledge: Subtest Economics]. Hannover: DGP.

Dörner, D. (1986). Diagnostik der operativen Intelligenz [Diagnostics of operative intelligence]. Diagnostica 32, 290-308.

Dörner, D. (1996). The Logic of Failure: Recognizing and Avoiding Error in Complex Situations. New York, NY: Basic Books.

Dörner, D., and Funke, J. (2017). Complex problem solving: what it is and what it is not. Front. Psychol. 8:1153. doi: 10.3389/fpsyg.2017.01153

Dörner, D., and Kreuzig, H. W. (1983). Problemlösefähigkeit und Intelligenz [Problem solving ability and intelligence]. Psychol. Rundsch. 34, 185-192.
Dörner, D., Kreuzig, H. W., Reither, F., and Stäudel, T. (1983). Lohhausen. Vom Umgang mit Unbestimmtheit und Komplexität [Lohhausen. About Dealing with Uncertainty and Complexity]. Bern: Huber.

Dutt, V., and Gonzalez, C. (2015). Accounting for outcome and process measures in dynamic decision-making tasks through model calibration. J. Dyn. Decis. Mak. 1, 1-10. doi: 10.11588/jddm.2015.1.17663

Engelhart, M., Funke, J., and Sager, S. (2017). A web-based feedback study on optimization-based training and analysis of human decision making. J. Dyn. Decis. Mak. 3, 1-23. doi: 10.11588/jddm.2017.1.34608

Fahrenberg, J. (2017). "Ökologische Validität [ecological validity]," in Dorsch Lexikon der Psychologie, ed. H. Wirz (Bern: Huber), 1202.

Fishbein, M., and Ajzen, I. (1974). Attitudes towards objects as predictors of single and multiple behavioral criteria. Psychol. Rev. 81, 59-74. doi: 10.1037/h0035872

Frensch, P. A., and Funke, J. (1995). "Definitions, traditions, and a general framework for understanding complex problem solving," in Complex Problem Solving. The European Perspective, eds P. A. Frensch and J. Funke (Hillsdale, NJ: Lawrence Erlbaum Associates), 3-25.

Funke, J. (1983). Einige Bemerkungen zu Problemen der Problemlöseforschung oder: Ist Testintelligenz doch ein Prädiktor? [Issues in problem solving research: is test intelligence a predictor after all?]. Diagnostica 29, 283-302.

Funke, J. (1985). Steuerung dynamischer Systeme durch Aufbau und Anwendung subjektiver Kausalmodelle [Control of dynamic systems by building up and using subjective causal models]. Z. Psychol. 193, 435-457.

Funke, J. (1992). Wissen über dynamische Systeme: Erwerb, Repräsentation und Anwendung [Knowledge About Dynamic Systems: Acquisition, Representation, and use]. Berlin: Springer. doi: 10.1007/978-3-642-77346-4

Funke, J. (1993). "Microworlds based on linear equation systems: a new approach to complex problem solving and experimental results," in The Cognitive Psychology of Knowledge, eds G. Strube and K.-F. Wender (Amsterdam: Elsevier), 313-330.

Funke, J. (1998). Computer-based testing and training with scenarios from complex problem solving research: advantages and disadvantages. Int. J. Sel. Assess. 6, 90-96. doi: 10.1111/1468-2389.00077

Funke, J. (2006). "Komplexes Problemlösen," in Denken und Problemlösen (Enzyklopädie der Psychologie, Serie II Kognition, Bd. 8, ed. J. Funke (Göttingen: Hogrefe), 375-445.

Funke, J. (2014). Analysis of minimal complex systems and complex problem solving require different forms of causal cognition. Front. Psychol. 5:739. doi: $10.3389 /$ fpsyg.2014.00739

Funke, J., Fischer, A., and Holt, V. D. (2017). When less is less: solving multiple simple problems is not complex problem solving-a comment on Greiff et al. (2015). J. Intell. 5:5. doi: 10.3390/jintelligence5010005

Funke, U. (1995). "Using complex problem solving tasks in personnel selection and training," in Complex Problem Solving. The European Perspective, eds P. A. Frensch and J. Funke (Hillsdale NJ: Erlbaum), 219-240.

Gigerenzer, G., and Gaissmaier, W. (2011). Heuristic decision making. Annu. Rev. Psychol. 62, 451-482. doi: 10.1146/annurev-psych-120709-145346

Gonzalez, C., and Dutt, V. (2011). A generic dynamic control task for behavioral research and education. Comput. Hum. Behav. 27, 1904-1914. doi: 10.1016/j. chb.2011.04.015

Gonzalez, C., Lerch, J. F., and Lebiere, C. (2003). Instance-based learning in dynamic decision making. Cogn. Sci. 27, 591-635. doi: 10.1016/S0364-0213(03) 00031-4

Goode, N., and Beckmann, J. F. (2010). You need to know: there is a causal relationship between structural knowledge and control performance in complex problem solving tasks. Intelligence 38, 345-352. doi: 10.1016/j.intell.2010. 01.001

Goode, N., and Beckmann, J. F. (2016). With a little help . . . on the role of guidance in the acquisition and utilisation of knowledge in the control of complex, dynamic systems. J. Dyn. Decis. Mak. 2:4. doi: 10.11588/jddm.2016.1.33346

Greiff, S., and Fischer, A. (2013). Der Nutzen einer komplexen Problemlösekompetenz: Theoretische Überlegungen und empirische Befunde [The value of complex problem solving competency: theoretical considerations and empirical results]. Z. Pädagog. Psychol. 27, 27-39. doi: 10.1024/1010-0652/a000086

Greiff, S., Fischer, A., Stadler, M., and Wüstenberg, S. (2015a). Assessing complex problem-solving skills with multiple complex systems. Think. Reason. 21, 356-382. doi: 10.1080/13546783.2014.989263 
Greiff, S., Kretzschmar, A., Müller, J. C., Spinath, B., and Martin, R. (2014). The computer-based assessment of complex problem solving and how it is influenced by students' information and communication technology literacy. J. Educ. Psychol. 106, 666-680. doi: 10.1037/a0035426

Greiff, S., Krkovic, K., and Hautamäki, J. (2016). The prediction of problem-solving assessed via microworlds a study on the relative relevance of fluid reasoning and working memory. Eur. J. Psychol. Assess. 32, 298-306. doi: 10.1027/1015-5759/ a000263

Greiff, S., Stadler, M., Sonnleitner, P., Wolff, C., and Martin, R. (2015b). Sometimes less is more: comparing the validity of complex problem solving measures. Intelligence 50, 100-113. doi: 10.1016/j.intell.2015.02.007

Greiff, S., Wüstenberg, S., and Funke, J. (2012). Dynamic problem solving: a new assessment perspective. Appl. Psychol. Meas. 36, 189-213. doi: 10.1177/ 0146621612439620

Greiff, S., Wüstenberg, S., Holt, D. V., Goldhammer, F., and Funke, J. (2013a). Computer-based assessment of Complex Problem Solving: concept, implementation, and application. Educ. Technol. Res. Dev. 61, 407-421. doi: 10.1007/s11423-013-9301-x

Greiff, S., Wüstenberg, S., Molnar, G., Fischer, A., Funke, J., and Csapo, B. (2013b). Complex problem solving in educational contexts-something beyond g: concept, assessment, measurement invariance, and construct validity. J. Educ. Psychol. 105, 364-379. doi: 10.1037/a0031856

Größler, A., Maier, F. H., and Milling, P. M. (2000). Enhancing learning capabilities by providing transparency in business simulators. Simul. Gaming 31, 257-278. doi: $10.1177 / 104687810003100209$

Gustafsson, J.-E., and Balke, G. (1993). General and specific abilities as predictors of school achievement. Multivariate Behav. Res. 28, 407-434. doi: 10.1207/ s15327906mbr2804_2

Haynes, S. N., Richard, D. C. S., and Kubany, E. S. (1995). Content validity in psychological assessment: a functional approach to concepts and methods. Psychol. Assess. 7, 238-247. doi: 10.1037/1040-3590.7.3.238

Herde, C. N., Wüstenberg, S., and Greiff, S. (2016). Assessment of complex problem solving: what we know and what we don't know. Appl. Meas. Educ. 29, 265-277. doi: 10.1080/08957347.2016.1209208

Hesse, F. W. (1982). Effekte des semantischen Kontextes auf die Bearbeitung komplexer Probleme [Effect of semantic context on the solution of complex problems]. Z. Exp. Angew. Psychol. 29, 62-91.

Horn, J. L. (2008). "Spearman, g, expertise, and the nature of human cognitive capability," in Extending Intelligence: Enhancement and New Constructs, eds P. C. Kyllonen, R. D. Roberts, and L. Stankov (New York, NY: Lawrence Erlbaum Associates), 185-230.

Horn, J. L., and Blankson, N. (2005). "Foundations for better understanding of cognitive abilities," in Contemporary Intellectual Assessment: Theories, Tests, and Issues, 2nd Edn, eds D. P. Flanagan and P. I. Harrison (New York, NY: Guilford Press), 41-68.

Jäger, A. O. (1982). Mehrmodale Klassifikation von Intelligenzleistungen. Experimentell kontrollierte Weiterentwicklung eines deskriptiven Intelligenzstrukturmodells [Multimodal classification of intellectual performance. Experimental development of a descriptive intelligence structure model]. Diagnostica 28, 195-226.

Jäger, A. O. (1984). Intelligenzstrukturforschung: Konkurrierende Modelle, neue Entwicklungen, Perspektiven [Intelligence structure research: competing models, new developments, perspectives]. Psychol. Rundsch. 35, 21-35.

Jäger, A. O., Süß, H.-M., and Beauducel, A. (1997). Test für das Berliner Intelligenzstrukturmodell. BIS-Test. Form 4 [Test for the Berlin Intelligence Structure Model]. Göttingen: Hogrefe.

Jensen, A. R., and Wang, L.-J. (1994). What is a good g? Intelligence 18, 231-258. doi: 10.1016/0160-2896(94)90029-9

Kerlinger, F. N., and Pedhazur, E. J. (1973). Multiple Regression in Behavioral Research. New York, NY: Holt, Rinehart and Winston.

Kersting, M. (2001). Zur Konstrukt- und Kriteriumsvalidität von Problemlöseszenarien anhand der Vorhersage von Vorgesetztenurteilen über die berufliche Bewährung [On the construct and criterion validity of problem-solving scenarios based on the prediction of supervisor assessment of job performance]. Diagnostica 47, 67-76. doi: 10.1026//0012-1924.47.2.67

Kersting, M., and Süß, H.-M. (1995). Kontentvalide Wissensdiagnostik und Problemlösen: Zur Entwicklung, testtheoretischen Begründung und empirischen Bewährung eines problemspezifischen Diagnoseverfahrens
[Content-valid diagnosis of knowledge and problem-solving: development, test theory justification, and empirical validation of a new problem-specific test]. Z. Pädagog. Psychol. 9, 83-93.

King, J., and Just, M. A. (1991). Individual differences in syntactic processing: the role of working memory. J. Mem. Lang. 30, 580-602. doi: 10.1016/0749596X(91)90027-H

Klauer, K. J. (1984). Kontentvalidität. [Content validity]. Diagnostica 30, $1-23$.

Kluge, A. (2008b). What you train is what you get? Task requirements and training methods in complex problem-solving. Comput. Hum. Behav. 24, 284-308. doi: 10.1016/j.chb.2007.01.013

Kluge, A. (2008a). Performance assessments with microworlds and their difficulty. Appl. Psychol. Meas. 32, 156-180. doi: 10.1177/0146621607300015

Kluwe, R. H., Misiak, C., and Haider, H. (1991). "The control of complex systems and performance in intelligence tests," in Intelligence: Reconceptualization and Measurement, ed. H. Rowe (Hillsdale: Lawrence Erlbaum Associates).

Kotter, J. P. (1982). What effective general managers really do. Harv. Bus. Rev. 60, $156-167$.

Kraemer, J. (2018). Die Lücke im Entscheidungsprozess. Die Bedeutsamkeit von Situationsbewusstsein und Optionsgenerierung für die Leistung von Fluglotsen [The Gap in Decision Making. The Significance of Situation Awareness and Option Generation for Air Traffic Controller Performance]. Köln: Deutsches Zentrum für Luft- und Raumfahrt e. V.

Kraemer, J., and Süß, H.-M. (2015). Real time validation of online situation awareness questionnaires in simulated approach air traffic control. Procedia Manuf. 3, 3152-3159. doi: 10.1016/j.promfg.2015.07.864

Kretzschmar, A. (2015). Konstruktvalidität des komplexen Problemlösens Unter Besonderer Berücksichtigung Moderner Diagnostischer Ansätze [Construct Validity of Complex Problem Solving With Particular Focus on Modern Assessment Approaches]. Doctoral dissertation, University of Luxembourg, Luxembourg.

Kretzschmar, A. (2017). Sometimes less is not enough: a commentary on Greiff et al. (2015). J. Intell. 5:4. doi: 10.3390/jintelligence5010004

Kretzschmar, A., Hacatrjana, L., and Rascevska, M. (2017). Re-evaluating the psychometric properties of MicroFIN: a multidimensional measurement of complex problem solving or a unidimensional reasoning test? Psychol. Test Assess. Model. 59, 157-182.

Kretzschmar, A., Neubert, J. C., and Greiff, S. (2014). Komplexes Problemlösen, schulfachliche Kompetenzen und ihre Relation zu Schulnoten [Complex problem solving, school competencies and their relation to school grades]. Z. Pädagog. Psychol. 28, 205-215. doi: 10.1024/1010-0652/ a000137

Kretzschmar, A., Neubert, J. C., Wüstenberg, S., and Greiff, S. (2016). Construct validity of complex problem solving: a comprehensive view on different facets of intelligence and school grades. Intelligence 54, 55-69. doi: 10.1016/j.intell. 2015.11.004

Kretzschmar, A., and Süß, H.-M. (2015). A study on the training of complex problem solving competence. J. Dyn. Decis. Mak. 1, 1-14. doi: 10.11588/jddm. 2015.1.15455

Kröner, S. (2001). Intelligenzdiagnostik per Computersimulation [Intelligence assessment via computer simulation]. Münster: Waxmann.

Kröner, S., Plass, J. L., and Leutner, D. (2005). Intelligence assessment with computer simulations. Intelligence 33, 347-368. doi: 10.1016/j.intell.2005. 03.002

Krumm, V., and Seidel, G. (1970). Wirtschaftslehretest [Economics Test]. Weinheim: Beltz.

Kyllonen, P. C., and Christal, R. E. (1990). Reasoning ability is (little more than) working-memory capacity?! Intelligence 14, 389-433. doi: 10.1016/S01602896(05)80012-1

Leutner, D. (2002). The fuzzy relationship of intelligence and problem solving in computer simulations. Comput. Hum. Behav. 18, 685-697. doi: 10.1016/s07475632(02)00024-9

Lotz, C., Scherer, R., Greiff, S., and Sparfeldt, J. R. (2017). Intelligence in action Effective strategic behaviors while solving complex problems. Intelligence 64, 98-112. doi: 10.1016/j.intell.2017.08.002

Lotz, C., Sparfeldt, J. R., and Greiff, S. (2016). Complex problem solving in educational contexts - Still something beyond a "good g"? Intelligence 59, 127-138. doi: 10.1016/j.intell.2016.09.001 
Maier, F. H., and Größler, A. (2000). What are we talking about? - A taxonomy of computer simulations to support learning. Syst. Dyn. Rev. 16, 135-148. doi: 10.1002/1099-1727(200022)16:2<135::AID-SDR193>3.0.CO;2-P

McGrew, K. S. (2005). “The Cattell-Horn-Carroll theory of cognitive abilities," in Contemporary Intellectual Assessment: Theories, Test, and Issues, 2nd Edn, eds D. P. Flanagan and P. L. Harrison (New York, NY: Guilford Press), 136-181.

McGrew, K. S. (2009). CHC theory and the human cognitive abilities project: standing on the shoulders of the giants of psychometric intelligence research. Intelligence 37, 1-10. doi: 10.1016/j.intell.2008.08.004

Milling, P. M. (1996). Modeling innovation processes for decision support and management simulation. Syst. Dyn. Rev. 12, 211-234. doi: 10.1002/(SICI)10991727(199623)12:3<211::AID-SDR105>3.0.CO;2-8

Mintzberg, H. (1973). The Nature of Managerial Work. New York, NY: Harper \& Row.

Morris, N. M., and Rouse, W. B. (1985). The effects of type of knowledge upon human problem solving in a process control task. IEEE Trans. Syst. Man Cybern. 15, 698-707. doi: 10.1109/TSMC.1985.6313453

Neubert, J. C., Kretzschmar, A., Wüstenberg, S., and Greiff, S. (2015). Extending the assessment of complex problem solving to finite state automata: embracing heterogeneity. Eur. J. Psychol. Assess. 31, 181-194. doi: 10.1027/1015-5759/ a000224

Oberauer, K., Süß, H.-M., Wilhelm, O., and Wittmann, W. W. (2003). The multiple faces of working memory: storage, processing, supervision, and coordination. Intelligence 31, 167-193. doi: 10.1016/S0160-2896(02)00115-0

Oberauer, K., Süß, H.-M., Wilhelm, O., and Wittmann, W. W. (2008). Which working memory functions predict intelligence? Intelligence 36, 641-652. doi: $10.1016 /$ j.intell.2008.01.007

OECD (2014). Pisa 2012 Results: Creative Problem Solving: Students' Skills in Tackling Real-Life Problems (Volume V). Paris: OECD Publishing. doi: 10.1787/ 9789264208070-en

Putz-Osterloh, W. (1981). Über die Beziehung zwischen Testintelligenz und Problemlöseerfolg [On the relationship between test intelligence and problem solving success]. Z. Psychol. 189, 79-100.

Rigas, G., Carling, E., and Brehmer, B. (2002). Reliability and validity of performance measures in microworlds. Intelligence 30, 463-480. doi: 10.1016/ S0160-2896(02)00121-6

Ryan, K. J. (2006). The Relationship Between Complex Problem Solving and Intelligence: An Analysis of Three Computer Simulated Scenarios. Doctoral dissertation, University of Sydney, Sydney.

Ryle, G. (1949). The Concept of Mind. London: Hutchinson.

Scherer, R. (2015). Is it time for a new measurement approach? A closer look at the assessment of cognitive adaptability in complex problem solving. Front. Psychol. 6:1664. doi: 10.3389/fpsyg.2015.01664

Scherer, R., and Tiemann, R. (2014). Measuring students' progressions in scientific problem solving: a psychometric approach. Procedia Soc. Behav. Sci. 112, 87-96. doi: 10.1016/j.sbspro.2014.01.1142

Schmid, J., and Leiman, J. M. (1957). The development of hierarchical factor solutions. Psychometrika 22, 53-61. doi: 10.1007/BF02289209

Schmidt, F. L. (1992). What do data really mean? Research findings, metaanalysis, and cumulative knowledge in psychology. Am. Psychol. 47, 1173-1181. doi: 10.1037/0003-066X.47.10.1173

Schmidt, F. L., Hunter, J. E., and Outerbridge, A. N. (1986). Impact of job experience and ability on job knowledge, work sample performance, and supervisory ratings of job performance. J. Appl. Psychol. 71, 432-439. doi: 10.1037/0021-9010.71.3.432

Schoppek, W., and Fischer, A. (2015). Complex problem solving-single ability or complex phenomenon? Front. Psychol. 6:1669. doi: 10.3389/fpsyg.2015.01669

Schweizer, F., Wüstenberg, S., and Greiff, S. (2013). Validity of the MicroDYN approach: complex problem solving predicts school grades beyond working memory capacity. Learn. Individ. Dif. 24, 42-52. doi: 10.1016/j.lindif.2012.12.011

Shadish, W. R., Cook, T. D., and Campbell, D. T. (2002). Experimental and Quasi-Experimental Designs for Generalized Causal Inference. Boston, MA: Houghton-Mifflin.

Sonnleitner, P., Brunner, M., Greiff, S., Funke, J., Keller, U., Martin, R., et al. (2012). The genetics lab: acceptance and psychometric characteristics of a computerbased microworld assessing complex problem solving. Psychol. Test Assess. Model. 54, 54-72. doi: 10.1037/e578442014-045
Sonnleitner, P., Keller, U., Martin, R., and Brunner, M. (2013). Students' complex problem-solving abilities: their structure and relations to reasoning ability and educational success. Intelligence 41, 289-305. doi: 10.1016/j.intell.2013. 05.002

Spearman, C. (1904). "General intelligence", objectively determined and measured. Am. J. Psychol. 15, 201-293. doi: 10.2307/1412107

Spering, M., Wagener, D., and Funke, J. (2005). The role of emotions in complex problem-solving. Cogn. Emot. 19, 1252-1261. doi: 10.1080/02699930500304886

Stadler, M. J., Becker, N., Gödker, M., Leutner, D., and Greiff, S. (2015). Complex problem solving and intelligence: a meta-analysis. Intelligence 53, 92-101. doi: 10.1016/j.intell.2015.09.005

Stadler, M. J., Becker, N., Greiff, S., and Spinath, F. M. (2016). The complex route to success: complex problem-solving skills in the prediction of university success. High. Educ. Res. Dev. 35, 365-379. doi: 10.1080/07294360.2015.1087387

Stankov, L. (2017). Overemphasized "g". J. Intell. 5:33. doi: 10.3390/ jintelligence 5040033

Süß, H.-M. (1996). Intelligenz, Wissen und Problemlösen. Kognitive Voraussetzungen für erfolgreiches Handeln bei computersimulierten Problemen [Intelligence, Knowledge, and Problem Solving: Cognitive Prerequisites of Successful Performance in Computer-Simulated Problems]. Lehr- und Forschungstexte Psychologie. Göttingen: Hogrefe.

Süß, H.-M. (1999). Intelligenz und komplexes Problemlösen: Perspektiven für eine Kooperation zwischen differentiell-psychometrischer und kognitionspsychologischer Forschung [Intelligence and complex problem solving: perspectives on the cooperation between differential-psychometric and cognitive research methods]. Psychol. Rundsch. 50, 220-228. doi: 10.1026//0033-3042.50.4.220

Süß, H.-M. (2001). “The predictive validity of reasoning and g in complex problem solving," in Paper Presented at the ISSID 2001 Conference, Edinburgh.

Süß, H.-M., and Beauducel, A. (2005). "Faceted models of intelligence," in Understanding and Measuring Intelligence, eds O. Wilhelm and R. Engle (Thousand Oaks, CA: Sage), 313-332.

Süß, H.-M., and Beauducel, A. (2011). "Intelligenztests und ihre Bezüge zu Intelligenztheorien. [Intelligence tests and their relationships to theories of intelligence]," in Leistungs-, Intelligenz- und Verhaltensdiagnostik (Enzyklopädie der Psychologie, Serie Psychologische Diagnostik, Bd. 3, eds L. F. Hornke, M. Amelang, and M. Kersting (Göttingen: Hogrefe), 97-234.

Süß, H.-M., and Beauducel, A. (2015). Modeling the construct validity of the Berlin intelligence structure model. Estud. Psicol. 32, 13-25. doi: 10.1590/0103166X2015000100002

Süß, H.-M., and Faulhaber, J. (1990). Berliner Version der Schneiderwerkstatt. PCSimulationsprogramm [Berlin Version of the Tailorshop]. Berlin: Freie Universität Berlin, Fachbereich Erziehungs- und Unterrichtswissenschaften, Institut für Psychologie.

Süß, H.-M., Kersting, M., and Oberauer, K. (1991). Intelligenz und Wissen als Prädiktoren für Leistungen bei computersimulierten komplexen Problemen [Intelligence and knowledge as predictors of performance in solving complex computer-simulated problems]. Diagnostica 37, 334-352.

Süß, H.-M., Kersting, M., and Oberauer, K. (1993a). Zur Vorhersage von Steuerungsleistungen an computersimulierten Systemen durch Wissen und Intelligenz [On the predictability of control performance on computersimulated systems by knowledge and intelligence]. Z. Differ. Diagnostische Psychol. 14, 189-203.

Süß, H.-M., Oberauer, K., and Kersting, M. (1993b). Intellektuelle Fähigkeiten und die Steuerung komplexer Systeme [Intelligence and control performance on computer-simulated systems]. Spr. Kognition 12, 83-97.

Süß, H.-M., Oberauer, K., Wittmann, W. W., Wilhelm, O., and Schulze, R. (2002). Working-memory capacity explains reasoning ability - And a little bit more. Intelligence 30, 261-288. doi: 10.1016/S0160-2896(01)00100-3

Swanson, L., and Kim, K. (2007). Working memory, short-term memory, and naming speed as predictors of children's mathematical performance. Intelligence 35, 151-168. doi: 10.1016/j.intell.2006.07.001

ten Have, J. M. (1993). The development of the NLR ATC Research Simulator (Narsim): design philosophy and potential for ATM research. Simul. Pract. Theory 1, 31-39. doi: 10.1016/0928-4869(93)90009-F

Vollmeyer, R., Burns, B. D., and Holyoak, K. J. (1996). The impact of goal specificity on strategy use and the acquisition of problem structure. Cogn. Sci. 20, 75-100. doi: $10.1207 /$ s15516709 $\operatorname{cog} 2001 \_3$ 
Wagener, D. (2001). Psychologische Diagnostik mit komplexen Szenarios Taxonomie, Entwicklung, Evaluation [Psychological Assessment with Complex Scenarios - Taxonomy, Development, Evaluation]. Lengerich: Pabst Science Publishers.

Wagener, D., and Wittmann, W. W. (2002). Personalarbeit mit dem komplexen Szenario FSYS [Human resource management using the complex scenario FSYS]. Z. Personalpsychologie 1, 80-93. doi: 10.1026//1617-6391. 1.2.80

Wallach, D. (1997). Kognitionswissenschaftliche Analysen komplexer Problemlöseprozesse [Cognitive Science Analyses of Complex Problem Solving Processes]. Wiesbaden: Westdeutscher Verlag.

Wittmann, W. W. (1988). "Multivariate reliability theory. Principles of symmetry and successful validation strategies," in Handbook of Multivariate Experimental Psychology, eds R. B. Cattell and J. R. Nesselroade (New York, NY: Plenum), 505-560. doi: 10.1007/978-1-4613-0893-5_16

Wittmann, W. W., and Hattrup, K. (2004). The relationship between performance in dynamic systems and intelligence. Syst. Res. Behav. Sci. 21, 393-409. doi: 10.1002/sres.653

Wittmann, W. W., and Süß, H.-M. (1999). "Investigating the paths between working memory, intelligence, knowledge, and complex problem-solving performances via Brunswik symmetry," in Learning and Individual Differences: Process, Trait and Content Determinants, eds P. L. Ackerman, P. C. Kyllonen, and R. D. Roberts (Washington, DC: APA), 77-104.
Wittmann, W. W., Süß, H.-M., and Oberauer, K. (1996). Determinanten komplexen Problemlösens [Determinants of Complex Problem Solving]. Research Report No. 9. Mannheim: Universität Mannheim.

Wolfe, J., and Roberts, C. R. (1986). The external validity of a business management game: a five-year longitudinal study. Simul. Games 17, 45-59. doi: 10.1177/ 0037550086171004

Wüstenberg, S., Greiff, S., and Funke, J. (2012). Complex problem solving - More than reasoning? Intelligence 40, 1-14. doi: 10.1016/j.intell.2011.11.003

Zech, A., Bühner, M., Kröner, S., Heene, M., and Hilbert, S. (2017). The impact of symmetry: explaining contradictory results concerning working memory, reasoning, and complex problem solving. J. Intell. 5:22. doi: 10.3390/ jintelligence 5020022

Conflict of Interest Statement: The authors declare that the research was conducted in the absence of any commercial or financial relationships that could be construed as a potential conflict of interest.

Copyright (C) 2018 Süß and Kretzschmar. This is an open-access article distributed under the terms of the Creative Commons Attribution License (CC BY). The use, distribution or reproduction in other forums is permitted, provided the original author(s) and the copyright owner are credited and that the original publication in this journal is cited, in accordance with accepted academic practice. No use, distribution or reproduction is permitted which does not comply with these terms. 